\title{
A NEW PERSPECTIVE ON COASTALLY TRAPPED DISTURBANCES USING DATA FROM THE SATELLITE ERA
}

\author{
Timothy W. Juliano, Zachary J. Lebo, Gregory Thompson, and David A. Rahn
}

\section{Satellite observations reveal that large-scale changes in the Pacific high may yield polluted coastal marine clouds and fogs associated with coastally trapped disturbances.}

C oastal marine environments are regions of significant meteorological interest as a result of the direct impact of atmospheric processes on, for example, commerce and trade, naval operations, and civilian activities. Low clouds and fogs, in particular, undoubtedly affect these sectors. Forecasting the life cycle (initiation, maintenance, and dissipation)

AFFILIATIONS: JULIANO* AND LEBO-Department of Atmospheric Science, University of Wyoming, Laramie, Wyoming; THOMPSONResearch Applications Laboratory, National Center for Atmospheric Research, Boulder, Colorado; RAHN-Department of Geography and Atmospheric Science, University of Kansas, Lawrence, Kansas

CURRENT AFFILIATION: JULIANO*-Research Applications Laboratory, National Center for Atmospheric Research, Boulder, Colorado CORRESPONDING AUTHOR: Zachary J. Lebo, zlebo@uwyo.edu

The abstract for this article can be found in this issue, following the table of contents.

DOI:I0.II75/BAMS-D-I8-0002.I

In final form 30 August 2018

(C2019 American Meteorological Society

For information regarding reuse of this content and general copyright information, consult the AMS Copyright Policy. and spatial and vertical coverage of these ubiquitous coastal clouds remains an outstanding challenge due to the inherently complex relationship between the ocean-land-atmosphere system (Boucher et al. 2013; Koraciin and Dorman 2017).

Considerable effort within the atmospheric science community focuses on marine boundary layer (MBL) stratiform clouds because their radiative response to changes in the climate system is substantial yet inconsistent between various global circulation models (e.g., Palmer and Anderson 1994; Delecluse et al. 1998; Bachiochi and Krishnamurti 2000; Bony and Dufresne 2005; Webb et al. 2006). Because their albedo (30\%-70\%; Randall et al. 1984; Koraciin and Dorman 2017) is relatively high compared to the ocean surface (10\%) and their temperature is nearly equal to that of the ocean surface, these cloud types exert an average shortwave (SW) radiative forcing of approximately $60-120 \mathrm{~W} \mathrm{~m}^{-2}$ (cooling effect; e.g., Hartmann et al. 1992; Zhang and Li 2013), although the magnitude is dependent on both macrophysical and microphysical properties (e.g., Twomey 1977; Albrecht 1989; Twohy et al. 1995, 2005; Wood 2012).

Low, marine clouds are expansive, as their global coverage is about one-third at any time and up to $\sim 60 \%$ over the subtropic and midlatitude oceanic 
regions near California, Peru, and Namibia during summer months (e.g., Klein and Hartmann 1993; Jiang et al. 2014). In the present study, we focus on the northeastern Pacific Ocean.

During the boreal warm season, the combination of the Pacific high and thermal low in the desert southwest of the United States leads to an MBL that slopes downward toward the east and supports northerly flow (e.g., Beardsley et al. 1987; Zemba and Friehe 1987; Parish 2000). A coastal jet sits at the base of a strong subsidence inversion (oftentimes $10^{\circ}-20^{\circ} \mathrm{C}$ ) that separates the cool, moist MBL from the warm, dry free troposphere above. Several times during each summer month, the strong, northerly winds weaken (also termed "relax"; e.g., Winant et al. 1987; Melton et al. 2009) and even reverse (e.g., Bond et al. 1996; Mass and Bond 1996).

The synoptic-scale conditions that support reversal events are marked by a migration and elongation of the Pacific high toward the northwestern United States (e.g., Mass and Bond 1996; Nuss et al. 2000). As a result, the offshore flow aloft strengthens, the MBL thins, and part of the cloud deck clears [see, e.g., Kloesel (1992) and Crosbie et al. (2016) for discussion of cloud clearings]. A reversal of the alongshore pressure gradient along the Northern California coastline occurs for two reasons: i) air descends from higher terrain over land to sea level and warms adiabatically and ii) warm air over land advects toward the MBL. Hence, the resultant pressure field preconditions the environment and becomes conducive for southerly flow. Bond et al. (1996) and Mass and Bond (1996) emphasize that the alongshore synoptic pressure gradient must deviate from climatology for a reversal to exist; that is, a southward-directed pressure gradient is required.

In the literature, these events are called wind reversals, southerly surges, coastally trapped wind reversals, or coastally trapped disturbances (CTDs). Here, we refer to them as CTDs. In the summer, CTDs occur along not only the western coast of the United States, but also the western coasts of South America (e.g., Garreaud et al. 2002; Garreaud and Rutllant 2003) and southern Africa (e.g., Gill 1977; Reason and Jury 1990), in addition to the southeastern coast of Australia (e.g., Holland and Leslie 1986; Reid and Leslie 1999; Reason et al. 1999). These phenomena are considered coastally trapped within $O(100) \mathrm{km}$ of the coastline as determined by the Rossby radius of deformation (e.g., Bond et al. 1996; Ralph et al. 1998).

The dynamics of CTDs have been debated in the literature over the last several decades, with a thorough review given by Nuss et al. (2000). Interpretations include a Kelvin wave (e.g., Dorman 1985), a topographic Rossby wave (Skamarock et al. 1999), a topographically trapped density current (e.g., Mass and Albright 1987), a combination Kelvin wave-bore (Ralph et al. 2000), and an ageostrophic response to the alongshore pressure gradient (e.g., Mass and Bond 1996). Regardless of the primary dynamical mechanism, observations and modeling results show that a broad region of stratus clouds and fogs often accompany these disturbances (e.g., Bond et al. 1996; Thompson et al. 2005; Rahn and Parish 2008). The microphysical properties of these clouds and fogs have received little attention in the literature and form the focus of the current study.

Figure 1 shows the temporal evolution of the MBL cloud field during the 22-25 June 2006 CTD case. Radar observations from this particular event are presented in Parish et al. (2008) and suggest that drizzle processes (accretion and selfcollection) may dominate over condensational growth of cloud droplets 
in localized cells; marine stratocumulus that are not associated with CTDs are known to show similar structure (e.g., Wood 2005; vanZanten et al. 2005).

A modeling investigation of the 15-16 June 2000 CTD case conducted by Thompson et al. (2005) finds that MBL depth and cloud extent are a strong function of buoyancy generation resulting from cloud-top radiative flux divergence and upward sea surface heat fluxes. Moreover, the wind shift at the leading edge of the CTD forces convergence and rising motion while preceding the stratus tongue and playing an important role in the distribution of cloud liquid water. The cloud deck to the south is found to lift off the surface and decouple due to entrainment of dry air resulting from KelvinHelmholtz instability at cloud top.

To the authors' best knowledge, however, the literature does not explicitly report comprehensively on aerosol-cloud and air-sea interactions in the context of CTDs. Therefore, the results from this study could provide a valuable test bed for better understanding and predicting aerosol-cloud-precipitation interactions in marine stratocumulus for both small- and large-scale modeling efforts.

EVENT SELECTION. The research presented here builds upon the 1981 to 1991 CTD climatology outlined in Bond et al. (1996) and Mass and Bond (1996) by considering the warm season (June-September) from 2004 to 2016. Potential CTD cases are first identified using wind data from the National Data Buoy Center (NDBC) - specifically, from buoy 46013 (Bodega Bay; see Fig. 1). The list of events is then filtered to
TABLE I. List of CTD events with corresponding buoy data availability. For each event, the first day refers to the initiation day (day 0 ). The data at each NDBC site are valid for a particular event (denoted by $X$ ) if the wind has a positive alongshore component for at least six consecutive hours on day 0 . (When the threshold is increased to 10 consecutive hours, only buoys $460 \mathrm{II}$ and 46014 are sensitive, most likely due to their geographical positions along the coastline.) Furthermore, if a buoy is missing data for one hour, then the meteorological variables are linearly interpolated. However, if a buoy is missing data for two or more consecutive hours, then the data for that particular event are considered invalid. These criteria are similar to those used in Bond et al. (1996).

\begin{tabular}{|c|c|c|c|c|c|c|}
\hline Year & Dates & 46011 & 46028 & 46042 & 46013 & 46014 \\
\hline 2004 & $16-18$ Jun & $x$ & $x$ & $x$ & $x$ & $x$ \\
\hline 2006 & $22-25$ Jun & $x$ & $x$ & $x$ & $x$ & \\
\hline 2007 & 6-7 Sep & $x$ & & $x$ & $x$ & $x$ \\
\hline \multirow[t]{3}{*}{2008} & $12-13$ Jun & $x$ & $x$ & $x$ & $x$ & $x$ \\
\hline & $27-28$ Jun & $x$ & $x$ & $x$ & $x$ & $x$ \\
\hline & 8-13 Jul & $x$ & $x$ & $x$ & $x$ & $x$ \\
\hline 2009 & 29 Jun-3 Jul & $x$ & $x$ & $x$ & $x$ & $x$ \\
\hline 2010 & 4-8 Jul & $x$ & $x$ & $x$ & $x$ & $x$ \\
\hline \multirow[t]{4}{*}{2011} & $27-28 \mathrm{Jul}$ & $x$ & $x$ & $x$ & $x$ & $x$ \\
\hline & I-5 Sep & $x$ & $x$ & $x$ & $x$ & $x$ \\
\hline & 10-II Sep & $x$ & $x$ & $x$ & $x$ & $x$ \\
\hline & 28-29 Sep & $x$ & $x$ & $x$ & $x$ & $x$ \\
\hline 2012 & $11-13 \mathrm{Sep}$ & & & $x$ & $x$ & $x$ \\
\hline 2013 & $3-5$ Jun & & $x$ & $x$ & $x$ & $x$ \\
\hline \multirow[t]{3}{*}{2014} & $9-10$ Jun & & $x$ & $x$ & $x$ & \\
\hline & 30 Jun-2 Jul & & $x$ & $x$ & $x$ & $x$ \\
\hline & 3-7 Sep & & $x$ & $x$ & $x$ & $x$ \\
\hline \multirow[t]{3}{*}{2015} & $16-18 \mathrm{Jul}$ & $x$ & & & $x$ & $x$ \\
\hline & $28-30 \mathrm{Jul}$ & & & $x$ & $x$ & \\
\hline & 17-19 Aug & & & $x$ & $x$ & \\
\hline \multirow[t]{3}{*}{2016} & $15-16 \mathrm{Jul}$ & $x$ & $x$ & $x$ & & \\
\hline & 17-19 Aug & & $x$ & $x$ & $x$ & $x$ \\
\hline & 7-10 Sep & $x$ & $x$ & $x$ & & \\
\hline
\end{tabular}

remove any landfalling cyclones, consistent with Bond et al. (1996). Visible satellite images are used in this filtering step. The Aqua Moderate Resolution Imaging Spectroradiometer (MODIS) imagery is interrogated qualitatively for the remaining $\sim 60$ events to ensure that the instrument could clearly observe each CTD cloud deck propagate northward over a period lasting at least 2 days with little to no contamination from clouds originating from other regions. After employing these techniques, a total of 23 cases are identified as clear CTDs with associated cloud fields.

The set of 23 cases is listed in Table 1. Five NDBC stations along the California coastline are chosen to 
confirm the presence of a CTD and to characterize the surface meteorology during the reversal. These buoys, from south to north, are 46011 (Santa Maria), 46028 (Cape San Martin), 46042 (Monterey), 46013 (Bodega Bay), and 46014 (Point Arena). The total number of valid events (see Table 1) at buoys 46011, $46028,46042,46013$, and 46014 are 15, 18, 22, 21, and 18 , respectively. Each event has valid data from at least two buoys: two events have valid data from two buoys, five events from three buoys, six events from four buoys, and 10 events from all five buoys. Using the buoy data, we identify day 0 as the day on which the wind reversal begins at buoy 46011 (see Table 1 for additional details).

REMOTE SENSING MEASUREMENTS. Data from 1-km level 2 Aqua MODIS retrievals allow for a new, comprehensive, and quantitative perspective on the cloud physical properties of the 23 CTD cases.

\begin{tabular}{|c|c|}
\hline Year & Dates \\
\hline 2004 & 9-1I Jun \\
\hline 2005 & $\begin{array}{c}23 \text { Jun-6 Jul } \\
27-3 \mid \text { Jul } \\
|6-2| \text { Aug }\end{array}$ \\
\hline 2006 & $\begin{array}{l}\text { 5-9 Jun } \\
2-4 \text { Jul }\end{array}$ \\
\hline 2007 & $23-26 \mathrm{Jul}$ \\
\hline 2008 & $\begin{array}{l}\text { |7-2| Jul } \\
3-9 \text { Aug } \\
22-24 \text { Aug }\end{array}$ \\
\hline 2009 & $\begin{array}{l}8-13 \text { Jun } \\
20-30 \text { Jul }\end{array}$ \\
\hline 2010 & I-12 Aug \\
\hline 2011 & $\begin{array}{l}7-13 \text { Jun } \\
11-16 \text { Jul } \\
\text { 3-7 Aug } \\
19-22 \text { Aug }\end{array}$ \\
\hline 2012 & $5-15 \mathrm{Jul}$ \\
\hline 2013 & 6-9 Jul \\
\hline 2014 & $\begin{array}{l}\text { 2-4 Jun } \\
\text { 17-20 Aug }\end{array}$ \\
\hline 2015 & 3l Aug-4 Sep \\
\hline 2016 & $\mathrm{I}-8 \mathrm{Jul}$ \\
\hline
\end{tabular}
tion of the case and the amount of contamination by clouds external to the CTD. Therefore, a total of 75 retrievals comprise the CTD cases. To compare with these cases, we use visible satellite images to compile a set of 23 nonCTD stratus and stratocumulus cases $^{1}$ (Table 2). A total of 141 retrievals comprise the non-CTD cases. For both the CTD and non-CTD composites, exactly one retrieval is used to represent the cloud field for each day.

Two key variables, cloud droplet effective radius ${ }^{2}$ $r_{e}$ and optical thickness ${ }^{3} \tau$, are retrieved by MODIS utilizing a bispectral solar reflectance method (Nakajima and King 1990). The 3.7- $\mu \mathrm{m}$ channel is used for the $r_{e}$ and $\tau$ retrievals because it best represents the actual value of $r_{e}$ at cloud top (Platnick 2000; Rausch et al. 2017).

The liquid water path (LWP) is then inferred from $r_{e}$ and $\tau$ and given by the relationship LWP $=$ $C \rho_{l} r_{e} \tau$, where $C$ is a function of the assumed vertical distribution of cloud liquid water and $\rho_{l}$ is the density of liquid water (Miller et al. 2016). We assume an approximately adiabatic $(C=5 / 9)$ cloud vertical profile whereby the cloud liquid water content is expected to increase approximately linearly with height (e.g., Wood and Hartmann 2006). Also, the cloud droplet number concentration is assumed to be roughly constant with height. Observational studies suggest that assuming an adiabatic or subadiabatic profile yields more realistic LWP results than when assuming a vertically homogeneous $(C=6 / 9)$ cloud profile (e.g., Brenguier et al. 2000; Wood 2005).

Data from the Advanced Scatterometer (ASCAT) aboard the European Organisation for the Exploitation of Meteorological Satellites (EUMETSAT) MetOp-A satellite are obtained from Remote Sensing Systems (RSS) and provide wind measurements over the ocean at $12.5-\mathrm{km}$ resolution. The microwave scatterometer operates at $5.255 \mathrm{GHz}(\sim 5.705 \mathrm{~cm}$; C band) and relates backscattered power to sea surface roughness, which correlates well with near-surface wind speed and direction. Optimally interpolated sea surface temperature (SST) data are also sourced from RSS and use the scheme developed in Reynolds and Smith (1994). The interpolated dataset utilized in this study combines retrieval methods at microwave and infrared wavelengths to yield high-resolution $(\sim 9 \mathrm{~km})$ SSTs under both clear and cloudy sky conditions.

\footnotetext{
${ }^{1}$ These cases are carefully selected to ensure the presence of a northerly flow regime under relatively quiescent synoptic conditions. We choose time periods with fairly persistent and continuous cloud decks because these qualities also characterize CTD clouds.

${ }^{2}$ Cloud droplet effective radius $r_{e}$ is defined as the ratio of the third moment to the second moment of the cloud droplet size distribution: $r_{e}=\int_{0}^{\infty} n(r) r^{3} d r / \int_{0}^{\infty} n(r) r^{2} d r$.

${ }^{3}$ Optical thickness $\tau$ is defined as the line integral of the extinction (absorption plus scattering) coefficient between levels $z_{1}$ and $z_{2}: \tau=\int_{z_{1}}^{z_{2}} \beta_{e}(z) d z$.
} 
SYNOPTIC CONDITIONS. We now examine changes in the large-scale dynamics and thermodynamics that occur when the Pacific high shifts toward the northeast prior to a CTD. Grids from the North American Mesoscale Forecast System (NAM) $12-\mathrm{km}$ analysis at 0000 UTC are analyzed for all 23 CTD cases. First, we average all 0000 UTC NAM grids $(97.7 \%$ availability) for June-September 2004-16 to produce a climatology. Then, we construct anomalies for each of the four days prior to a CTD and for the day of the initiation (days -4 to 0 ) using the 0000 UTC NAM grids (Fig. 2).

During the warm season, the Pacific high typically resides hundreds of kilometers west of California and generates low-level, northerly flow along the shore; winds at $850 \mathrm{hPa}$ are approximately $5-8 \mathrm{~m} \mathrm{~s}^{-1}$. The isobaric surface slopes downward toward the coast as the 850-hPa temperatures increase to the east. At $850 \mathrm{hPa}$, the cross-coast height gradient is strongest ( 5 m per $100 \mathrm{~km}$ ) and directed away from the coastline offshore Northern California; the height gradient decreases in magnitude with decreasing latitude. Average conditions at $500 \mathrm{hPa}$ reveal a mostly zonal (westerly) flow with a weak trough offshore. Three to four days before a CTD initiates, the largescale conditions are similar to climatology, although the position of the anticyclone is slightly south, as indicated by the anomalously low sea level pressure (SLP) values and $850-\mathrm{hPa}$ heights to the north. The 850-hPa temperatures are slightly below (above) average north (south) of central California along the coastline, while at $500 \mathrm{hPa}$ they are generally above average offshore California. Diffluence occurs at $850 \mathrm{hPa}$ near $130^{\circ} \mathrm{W}$, and the zonal flow at $500 \mathrm{hPa}$ is greater than climatology.

Over the next several days, the Pacific high shifts northeastward and strengthens noticeably, and the

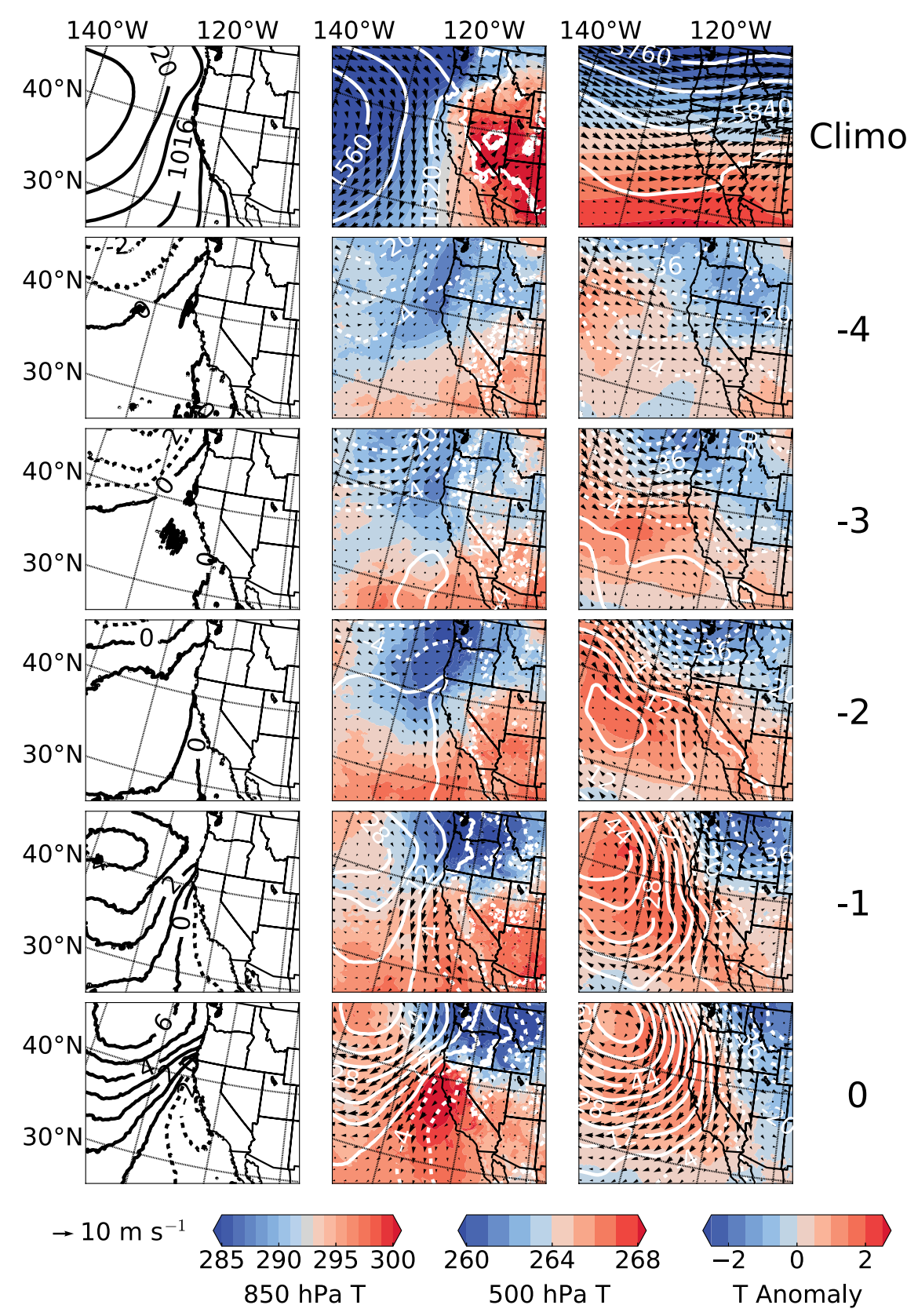

FIG. 2. Composites of 0000 UTC I2-km NAM grids: (left) SLP (black contours; units in $\mathrm{hPa}$ ), and (middle) 850-hPa and (right) 500-hPa height (white contours; $\mathrm{m}$ ), wind arrows, and temperature (color contoured with color bar; $K$ ). The topmost panel shows the climatological average, while the following five panels show the anomalies relative to climatology for days $-4,-3,-2,-1$, and 0 . For the anomaly plots, solid (dashed) contours indicate positive (negative) values. A reference wind vector is also plotted. 
thermal low pressure extends offshore Southern California, causing a tighter pressure gradient. An enhancement in the northerly flow is observed at $850 \mathrm{hPa}$; wind speeds exceed $10 \mathrm{~m} \mathrm{~s}^{-1}$ in many areas. Troughing along the Northern California coast is evident on day -1 as offshore continental flow begins and $850-\mathrm{hPa}$ temperatures increase. On the day that a typical CTD initiates (day 0), SLP values are greater than $1028 \mathrm{hPa}-$ more than $6 \mathrm{hPa}(8 \mathrm{hPa})$ greater than climatology (on day -3 ) - around $42^{\circ} \mathrm{N}$, $135^{\circ} \mathrm{W}$. The SLP anomaly near central California on day 0 is about $-3 \mathrm{hPa}$. A slight rotation in the $850-\mathrm{hPa}$ height contours fosters additional offshore flow; the 850 -hPa height gradient, which increases to $\sim 15 \mathrm{~m}$ per $100 \mathrm{~km}$ offshore Northern California, reverses sign near Monterey Bay to become directed toward the coastline (not shown). This additional tightening of the height gradient leads to even stronger winds offshore that are blowing from the north-northeast. Adiabatic descent and warm air advection induces troughing along the California coast as far north as Cape Mendocino. At $500 \mathrm{hPa}$, a ridge-trough pattern develops offshore Northern California. A similar evolution in both the lower- and upper-level conditions are reported in the Mass and Bond (1996) analysis.

The synoptic-scale composites in Fig. 2 are representative of all 23 CTD events as determined by a qualitative analysis of the NAM grids for each event. This is confirmed through a statistical evaluation whereby we consider each variable for day -4 through day 0 . The percentage area over the oceanic domain illustrated in Fig. 2 that is statistically significant at the $95 \%$ confidence level is listed for all variables in Table 3. The number of statistically significant grid boxes is smallest for all variables on day -4 , reiterating that conditions deviate little from climatology.

\begin{tabular}{|c|c|c|c|c|c|}
\hline & Day -4 & Day -3 & Day -2 & Day -I & Day 0 \\
\hline SLP & 0.1 & 2.0 & 35.7 & 80.1 & 77.1 \\
\hline $850-\mathrm{hPa} u$ & 1.2 & 24.0 & 18.1 & 25.3 & 63.8 \\
\hline $500-\mathrm{hPa} u$ & 1.1 & 22.3 & 30.2 & 25.1 & 64.9 \\
\hline $850-\mathrm{hPa} v$ & 4.3 & 14.7 & 24.2 & 48.6 & 62.1 \\
\hline $500-\mathrm{hPa} v$ & 4.1 & 15.8 & 60.0 & 58.8 & 51.6 \\
\hline $850-\mathrm{hPa} Z$ & 0.0 & 4.7 & 28.3 & 70.3 & 71.9 \\
\hline $500-\mathrm{hPa} Z$ & 19.5 & 22.2 & 55.6 & 67.0 & 65.2 \\
\hline $850-\mathrm{hPa} T$ & 0.1 & 11.3 & 38.0 & 33.4 & 46.0 \\
\hline $500-\mathrm{hPa} T$ & 3.5 & 33.8 & 65.2 & 72.1 & 43.0 \\
\hline
\end{tabular}

Unsurprisingly, the percentage of statistically significant areas increases toward day 0 and is greatest on day $-2,-1$, or 0 for all variables. Greater than $60 \%$ of the oceanic region is statistically significant for seven of eight variables on at least one day, which justifies the claim that the large-scale meteorological conditions are perturbed substantially preceding the inception of a CTD.

AIR-SEA INTERACTIONS. Changes in SSTs over the 14-day period surrounding the initiation of a CTD are shown in Fig. 3. The actual SST and surface wind fields are plotted for day 0 , while the anomalies relative to day 0 are shown for all other days. About a week prior to the CTD, low-level, offshore winds weaken to decrease ocean upwelling and increase SSTs. A large swath of SST anomalies greater than $+0.5^{\circ} \mathrm{C}$ are observed. Maximum warming is seen off the Northern California coast around days -3 and -2 .

The offshore winds then begin to increase in accordance with the strengthening SLP gradient; the strongest northerly winds are observed on the day that a typical CTD commences (day 0). Because upwellingfavorable winds are enhanced, SSTs decrease from day -1 to +3 offshore Northern California. Anomalies approach $-0.5^{\circ} \mathrm{C}$ and lead to a net decrease in SST of more than $1.0^{\circ} \mathrm{C}$ over 4 days across $\sim 50,000 \mathrm{~km}^{2}$. A lag of 2-3 days is observed between the changing sea surface wind stress and subsequent SST anomaly. A lag in cooling SSTs following the reestablishment of northerly winds after a relaxation event is described in Goela et al. (2016).

As expected, the southerly flow associated with the CTD extends northward over time and disrupts the upwelling regime beginning at day 0 . After day +2 , the SST anomalies increase significantly, and by day +7 , anomalies reach a maximum in magnitude and spatial extent: warm anomalies exceed $+1.0^{\circ} \mathrm{C}$ in many areas and are statistically significant at the $90 \%$ confidence level over $\sim 350,000 \mathrm{~km}^{2}$ (hatched region in Fig. 3).

The three-stage cycle in near-surface winds and SSTs here is similar to that identified by Fewings et al. (2016) and Flynn et al. (2017) during wind relaxation events. The authors note that, on average, the 

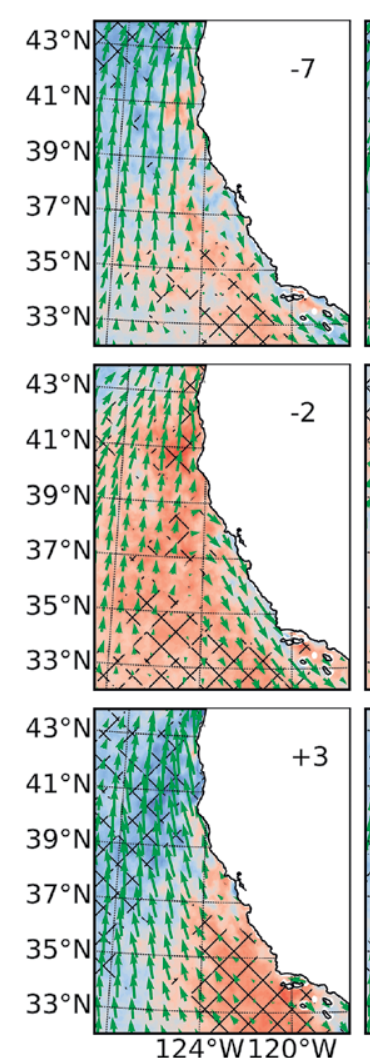

$124^{\circ} \mathrm{W} 120^{\circ} \mathrm{W}$
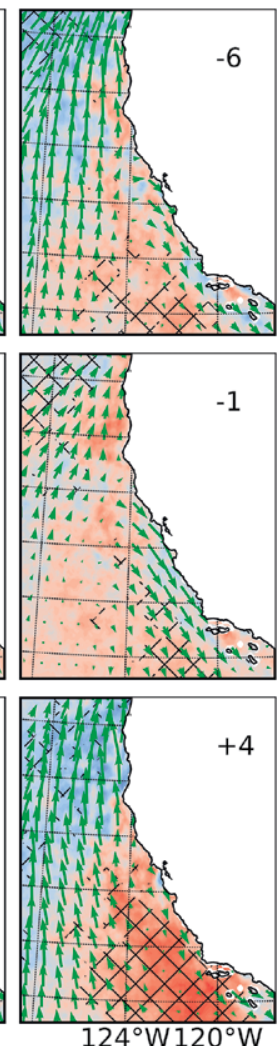
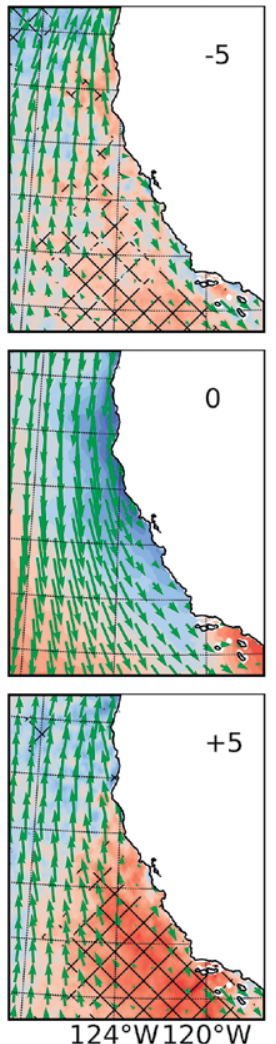
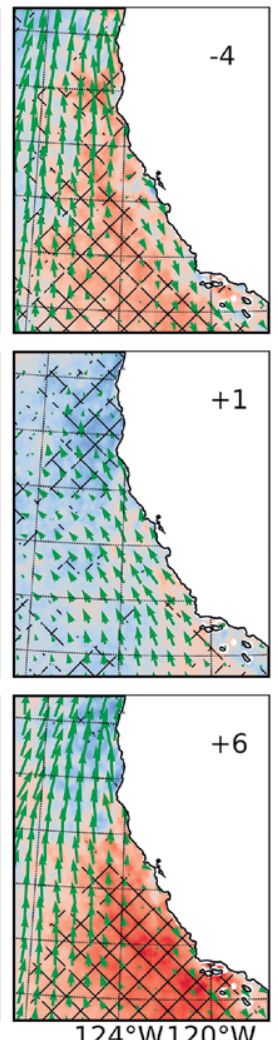
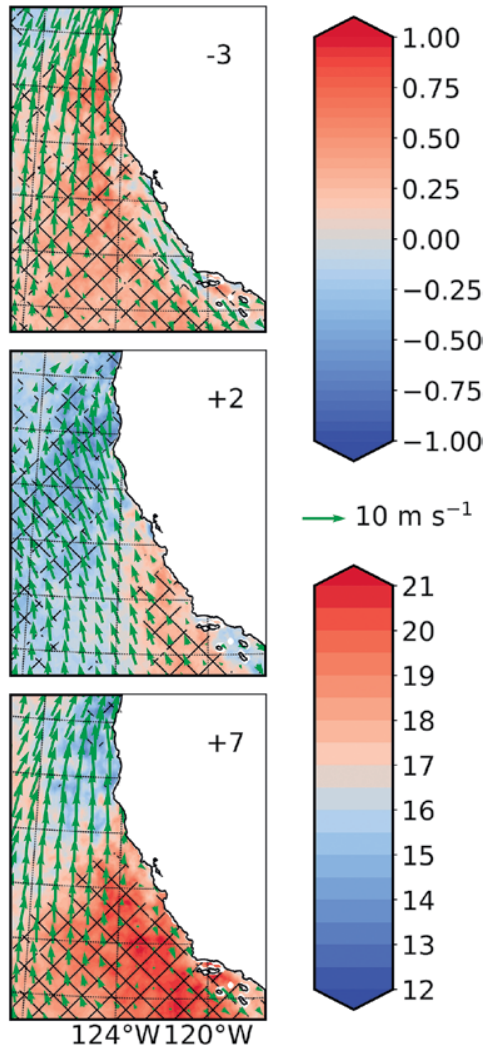

$\longrightarrow 10 \mathrm{~m} \mathrm{~s}^{-1}$

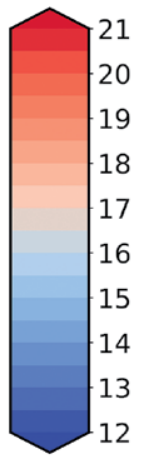

FIG. 3. Composites of SST and surface wind from satellite observations. Numbers in the top-right corner of each panel refer to the day relative to the initiation of a CTD (day 0 ). The actual SST and wind fields are plotted for day $\mathbf{0}$, while the anomalies relative to day 0 are shown for all other days. The hatching indicates regions of SST anomalies that are statistically significant at the $\mathbf{9 0 \%}$ confidence level. The top and bottom color bars refer to SST anomalies and the actual SST field (units in ${ }^{\circ} \mathrm{C}$ ), respectively. A reference wind vector is also shown. Wind data are not available for the 2004 and 2006 CTD cases.

wind stress does not reverse sign. While this suggests that downwelling-favorable conditions are not common in their study, such conditions are commonplace during a CTD. We suspect that the underlying cause for the difference in downwelling frequency is due to the strength of the Pacific high: anomalies in SLP one day before a typical wind relaxation event began are only $\sim 2 \mathrm{hPa}$ (Fewings et al. 2016).

SURFACE TRANSITION. Hourly observations at each of the five buoy stations for all valid events are analyzed for the 24-h period across each CTD (Fig. 4). Each event is normalized such that the time when the buoy first reports northward flow is at the center of the plot (0 h). Similar to the Bond et al. (1996) study, most of the CTDs begin propagating overnight or in the early morning hours (typically between 0000 and 1200 UTC on day 0). The initiation and surging of a CTD overnight are tied to diabatic processes. Daytime heating enhances the cross-coast pressure gradient that favors northerly wind near the coast (Beardsley et al. 1987), which inhibits the formation of a CTD during the day. At night, the temperature in the cloud-free region north of the CTD changes little compared to the cloudy region of the incipient CTD, where the temperature decreases rapidly and the MBL deepens due to cloud-top longwave radiative cooling. The increased density contrast produces a northward acceleration along the coast and is responsible for the characteristic surge overnight and into the morning (Rahn and Parish 2008).

A stark contrast in the wind speed and direction is evident at nearly all buoys. Twelve hours prior to a CTD, the surface wind speed is typically around $5 \mathrm{~m} \mathrm{~s}^{-1}$ except for buoy 46011, where the wind speed is slightly weaker. At all buoy sites, wind speeds decrease as the CTD approaches. A weak, positive cross-coast component-indicating onshore flow-is evident at all buoy sites except buoy 46014, where values are slightly negative. Leading up to the reversal, strong negative alongshore (southward) winds are apparent. At the time of the reversal, a minimum in the wind speed and magnitude of the alongshore component is observed. After the leading edge of 
the CTD passes, wind speeds begin to increase and reach a maximum by about +3 to $+6 \mathrm{~h}$. The signal in the cross-coast component is not consistent between the buoys; only buoy 46014 shows a clear signal with offshore (onshore) flow ahead of (behind) the CTD. As expected, however, the alongshore wind turns positive and is approximately $3-4 \mathrm{~m} \mathrm{~s}^{-1}$ on average.

The number of strong CTD events (alongshore component of at least $5 \mathrm{~m} \mathrm{~s}^{-1}$ for at least one report) at buoys 46011, 46028, 46042, 46013, and 46014 is 3 (20\% of all valid events), 8 (44\%), 9 (41\%), 12 (57\%), and $11(61 \%)$, respectively. These frequencies suggest that the northern sites are more likely to experience stronger alongshore winds within the CTD. We hypothesize that CTDs usually initiate near the southern locations, so they tend to be less developed and weaker, while the northern locations are more representative of well-developed and stronger CTDs that surge northward along the coast. Overall, we find that the probability of observing a strong CTD event is much greater than previously reported $(\sim 10 \%-15 \%$; Bond et al. 1996).
Pressure and air temperature perturbations are also evaluated during the transition from northerly to southerly flow. For each event, the pressure and temperature at the time of the CTD $(0 \mathrm{~h})$ are considered the mean values. Pressure generally reaches a minimum about $3-6 \mathrm{~h}$ before the reversal. Air temperature is relatively high prior to the CTD, although buoy 46042 shows slightly lower temperature during these times. During the $12 \mathrm{~h}$ following a typical CTD, the pressure at each buoy rises. This pressure increase after the passage of a CTD has been previously noted (e.g., Bond et al. 1996; Parish et al. 2008). Temperature observations also show an increase after the passage, with a minimum typically occurring at or just after the wind shift. The temperature for buoy 46042 does not show this coherent trend. Monterey Bay influences the buoy 46042 measurements because the change in coastline geometry and the presence of complex terrain may significantly alter the CTD propagation and the land-sea breeze circulation (Banta et al. 1993). Satellite imagery regularly shows that the flow at the head of the CTD
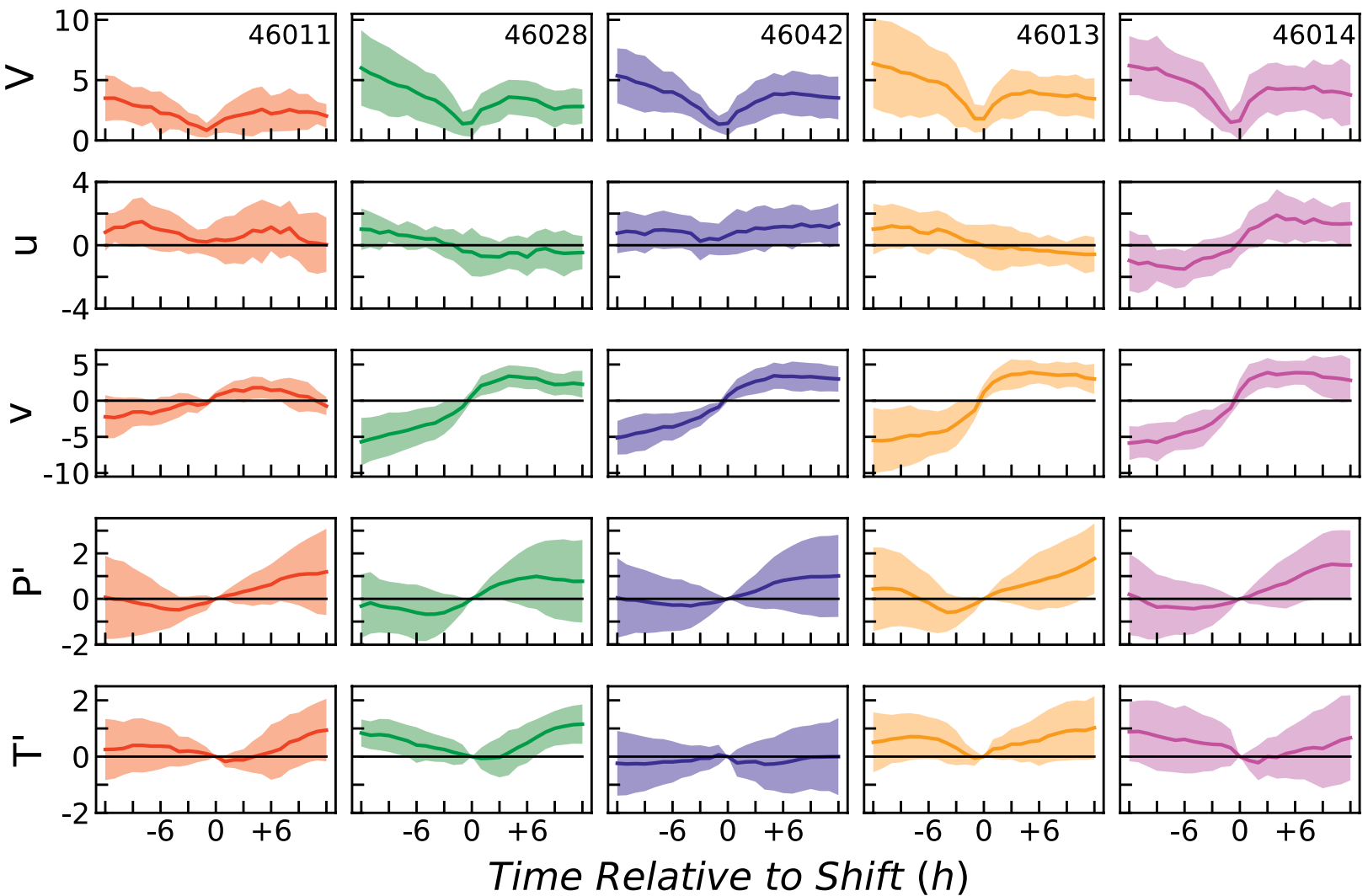

FIG. 4. Time series of horizontal wind speed (V; units in $\left.\mathrm{m} \mathrm{s}^{-1}\right)$, cross-coast wind speed (u; $\left.\mathrm{m} \mathrm{s}^{-1}\right)$, alongshore wind speed $\left(v ; \mathrm{m} \mathrm{s}^{-1}\right)$, pressure perturbation $\left(\mathrm{P}^{\prime} ; \mathrm{hPa}\right)$, and temperature perturbation $\left(T^{\prime} ;{ }^{\circ} \mathrm{C}\right)$. The coordinate system is rotated $30^{\circ}$ to align approximately with the coastline such that the cross-coast (u) and alongshore (v) wind components are defined as $330^{\circ}$ and $60^{\circ}$, respectively, in accordance with Ralph et al. (2000) and Parish et al. (2008). Buoy observations are arranged from south on the left to north on the right. 
follows the coastline into Monterey Bay and the low cloud is often seen entering the Salinas Valley south of the bay before the CTD continues northward along the coast. Overall, the air temperature analysis here differs from the CTD climatology by Bond et al. (1996), where buoy data indicated little trend.

The discrepancies in the i) number of strong CTD events and ii) alongshore temperature gradient between the Bond et al. (1996) study and present study may be attributed to the case selection process. Because more than half of our cases propagate north of Cape Mendocino, we hypothesize that the average synoptic-scale, alongshore pressure gradient on the order of $1 \mathrm{hPa}$ per $100 \mathrm{~km}$ driving the CTDs considered here, which is stronger than that found in the Bond et al. (1996) results, increases the in-cloud wind speed. A strong alongshore pressure gradient is due to strong offshore flow that enhances subsidence and inversion strength, which act to decrease cloud-top

Fig. 5. Mean microphysical parameters contoured for (left) CTD and (middle) nonCTD events along with the (right) difference (CTD minus non-CTD). Positive (negative) differences indicate larger (smaller) values during CTD events. Properties shown include $r_{\mathrm{e}}$ (units in $\mu \mathrm{m}$ ), $\tau$ (unitless), LWP $\left(\mathrm{g} \mathrm{m}^{-2}\right), \mathrm{N}\left(\mathrm{cm}^{-3}\right)$, and $H(m)$. The number of samples $n$ at each location is also color contoured. We contour the $n=37$ line $(\sim 54 \%$ of $\boldsymbol{n}_{\max }$ for CTD cases) in bold white to provide a visual for the approximate mean cloud deck extent during a mature CTD. We consider all days listed in Tables $I$ and 2. The $\mathrm{I}-\mathrm{km}$ MODIS retrievals are interpolated to a regular $1 / 20^{\circ} \times$ $1 / 20^{\circ}(\sim 5 \mathrm{~km} \times 5 \mathrm{~km})$ grid using inverse distance weighting. entrainment and maintain the cloud layer (e.g., Wood and Bretherton 2006; Iacobellis and Cayan 2013). Because a well-developed cloud deck is present in all 23 cases here, the average CTD may be characterized by an alongshore thermal gradient that is stronger than that found for the typical CTD in Bond et al. (1996).

CONTRASTING CLOUD REGIMES. We now compare CTD cloud characteristics with those for
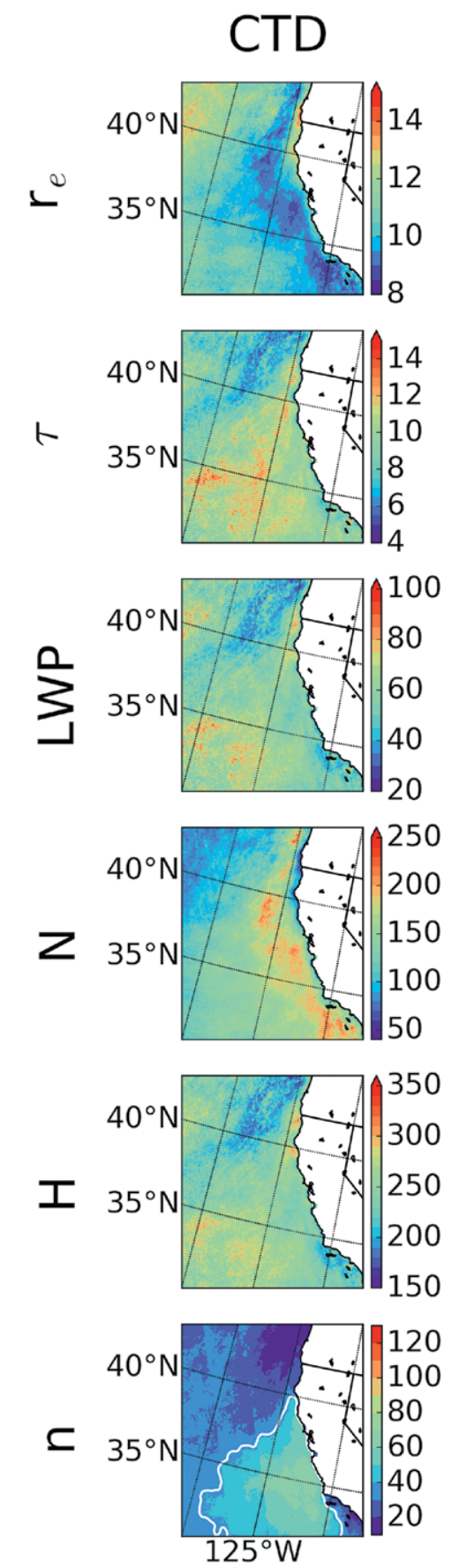
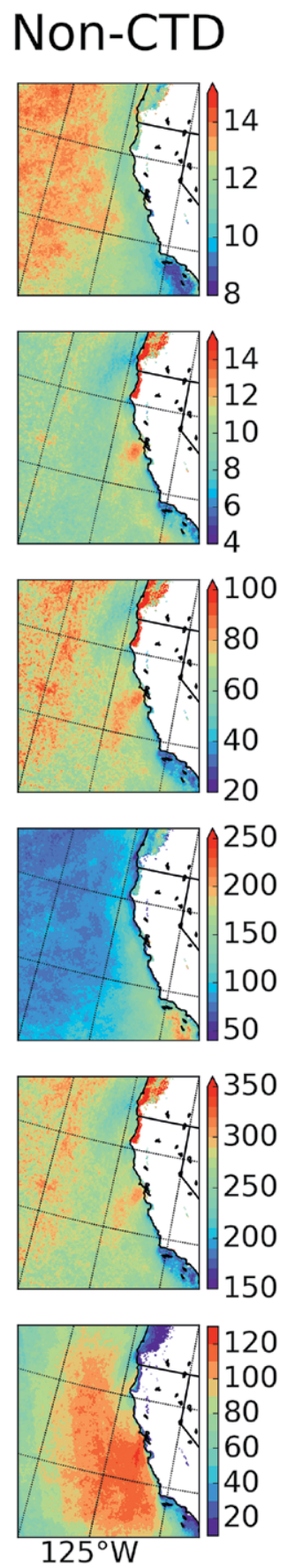

Diff.
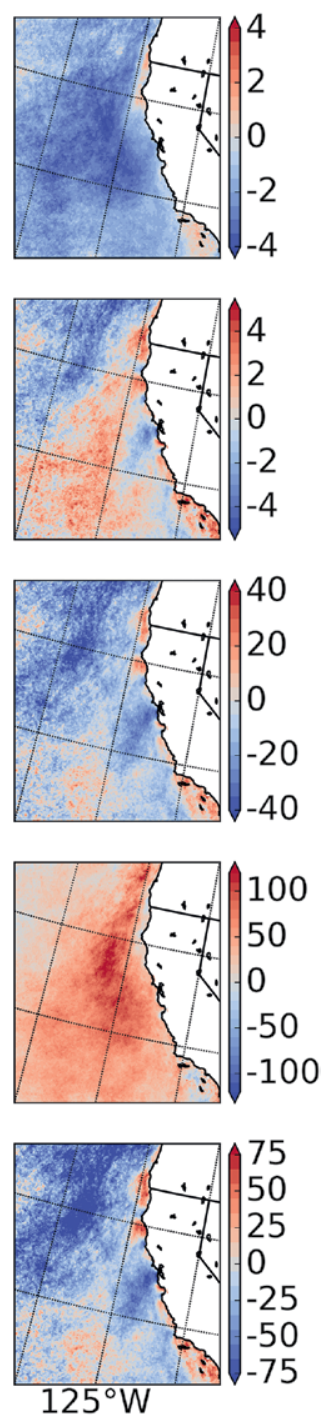
marine clouds during non-CTD events (Fig. 5; also see sidebar "Estimates of cloud depth and cloud droplet number concentration"). Several key distinctions between cloud regimes are evident. Minimum values of $r_{e}(\sim 8-10 \mu \mathrm{m})$ are observed in a large swath west of the U.S. coastline during the CTD cases. During the non-CTD events, however, $r_{e}$ is much greater offshore; in many regions, differences in $r_{e}$ between the CTD and non-CTD events exceed $3 \mu \mathrm{m}(\sim 20 \%-40 \%)$. Accompanying the relatively small values of $r_{e}$ are large values of $N$. Values approach $250 \mathrm{~cm}^{-3}$ during CTDs and are nearly a factor of 2 greater compared

\section{ESTIMATES OF CLOUD DEPTH}

\section{AND CLOUD DROPLET NUMBER CONCENTRATION}

$C_{n}^{2}$ oud depth $\mathrm{H}$ and cloud droplet number concentration $\mathrm{N}$ may be derived from observations of $\tau$ and LWP after assuming an adiabatic cloud model (Bennartz 2007). These relationships [Eqs. (8) and (9) in Bennartz 2007] are expressed as follows:

$$
H=\left(2 \frac{\mathrm{LWP}}{c_{w} C_{F}}\right)^{1 / 2}
$$

$N=\frac{2^{-5 / 2}}{k} \tau^{3}\left(\frac{\mathrm{LWP}}{C_{F}}\right)^{-5 / 2}\left(\frac{3}{5} \pi \mathrm{Q}\right)^{-3}\left(\frac{3}{4 \pi \rho_{l}}\right)^{-2} c_{w}^{1 / 2}$,

where $c_{w}$ is the condensation rate (often called the liquid water content lapse rate) in $\mathrm{kg} \mathrm{m}^{-4}, C_{F}$ is the fraction of warm clouds, $k$ is the ratio between the volume mean radius and the effective radius to the third power, and $Q$ is the scattering efficiency. We calculate the condensation rate, which is a function of cloud base temperature and pressure, for each $\mathrm{I} \times \mathrm{I} \mathrm{km}^{2}$ grid box containing cloud. Cloud-top temperature and pressure are derived from the MODIS retrievals. Due to the shallow nature of MBL clouds, we assume that i) cloud base temperature is equal to cloud-top temperature and ii) cloud-base pressure is $25 \mathrm{hPa}$ greater than cloud-top pressure. Furthermore, Lu and Seinfeld (2006) report that $k$ varies between 0.5 and 0.9 , and so we choose a value of 0.8 following Bennartz and Rausch (2017). Finally, $Q=2$ is consistent with Mie theory because cloud droplets are much larger than the incident solar radiation (size parameter $\gamma \geq 30$; Bennartz 2007). For a review of limitations and sensitivities relating to estimates of $N$ from Aqua MODIS retrievals, the reader is referred to the recent discussion by Bennartz and Rausch (2017). to non-CTDs in many areas. For nearly all points in the domain, $N$ is, on average, greater during CTD than non-CTD cases.

Capes and points along the coastline appear to modify the cloud field during CTD events. An increase in $r_{e}(\sim 10-14 \mu \mathrm{m})$ is observed close to the shoreline with maximum values adjacent to the coast found near the California-Oregon border. However, the sample size near the coast north of Cape Mendocino is small because not all of the CTDs propagate to this region. Pockets of diminished $N\left(\sim 50-150 \mathrm{~cm}^{-3}\right)$ are also present in these areas. Overall, differences in $r_{e}, \tau$, LWP, and $H$ between the CTD and non-CTD cases display a dipole pattern on the northern and southern locations of capes and points. Positive (negative) differences in these variables are observed on the south (north) side of terrain features. We hypothesize that because points and capes act as barriers to and induce hydraulic features within the marine flow, they modify localscale dynamics, cloud layer depth, and microphysical processes (e.g., condensational growth, entrainment, and drizzle production). For instance, flow convergence upstream of a barrier may promote cloud layer deepening (e.g., due to an oblique hydraulic jump; see Haack et al. 2001), while flow divergence downstream of a barrier may promote cloud layer thinning (e.g., due to an expansion fan; see Juliano et al. 2017). Future high-resolution modeling studies should be performed to test this hypothesis.

Frequency distributions plotted in Fig. 6 confirm the disparity in $r_{e}$ and $N$ between CTD and non-CTD events. The $r_{e}$ distribution for CTD cases is relatively narrow and has a peak around $8 \mu \mathrm{m}$. The peak is also around $8 \mu \mathrm{m}$ for non-CTD cases, but the distribution is much broader with a tail that falls off much slower. Both distributions are right-tailed. Due to the inverse relationship between $r_{e}$ and $N$, the peak of the $N$ distribution occurs at $\sim 40 \mathrm{~cm}^{-3}$ for non-CTD cases and $\sim 110 \mathrm{~cm}^{-3}$ for CTD cases. Similar to the $r_{e}$ distribution, both $N$ distributions are positively skewed, and the one for non-CTDs falls off quickly, while there are many more instances of large $N\left(>150 \mathrm{~cm}^{-3}\right)$ during CTDs. Differences in $\tau$, LWP, and $H$ between CTD and non-CTD cloud regimes are not as large, although there are generally more instances of optically thicker (larger $\tau$ ) and shallower (smaller $H$ and LWP) clouds associated with CTDs.

Normalized joint probability density functions are used to highlight CTD and non-CTD differences in the cloud physics (Fig. 7). As has been the common theme, the likelihood of observing clouds with more numerous $(N)$ and smaller $\left(r_{e}\right)$ droplets is higher in CTD cloud 
decks than in typical marine stratus and stratocumulus decks. These CTD clouds with high $N$ may be relatively shallow or deep (and therefore characterized by low or high LWP) and optically thin or thick (small or large $\tau)$. Once the number of cloud droplets approaches $\sim 250 \mathrm{~cm}^{-3}$, however, $H$, LWP, and $\tau$ converge toward $\sim 175 \mathrm{~m}, \sim 40 \mathrm{~g} \mathrm{~m}^{-2}$, and $\sim 7.5$, respectively. Moreover, when relatively shallow MBL clouds are present, there is a higher probability of observing optically thicker (thinner) clouds in CTD (non-CTD) cases because $N$ is typically larger during CTD events.

\section{CLOUD DROPLET NUMBER CONCEN- TRATION ENHANCEMENT. Through MODIS} retrievals, we show that marine stratiform clouds accompanying CTDs exhibit, on average, a clear increase in cloud droplet number concentration $N$ when compared to $N$ in marine clouds that develop during the typical northerly wind regime (nonCTDs). We hypothesize that the fundamental cause for this substantial increase in the number of cloud droplets is threefold:

i) The observed wind stress-SST cycle promotes mixing of sea salt aerosol into the MBL. ii) Before entering the cloud deck, CTD air parcels spend a considerable amount of time passing through major shipping lanes.

iii) Offshore continental flow, which is a requirement for the initiation of a CTD, transports continental aerosol into the marine layer.

We depict these three processes using schematics (Fig. 8) and elaborate with the following discussion.

Sea salt aerosol concentration is known to depend strongly on surface wind speed (e.g., Gong 2003; Pierce and Adams 2006; Feng et al. 2017). We suspect that as northerly winds offshore of California ramp up immediately preceding a CTD, elevated ocean stress leads to an increase in sea spray and sea salt particles mixing into the MBL (Fig. 8, top panel). Given that their residence time, which is inversely proportional to particle size, may range from $30 \mathrm{~min}$ to over 2 days (e.g., Lovett 1978; Gong et al. 1997; Jaeglé et al. 2011), sea salt aerosol may efficiently mix into CTD clouds due to strong convergence (e.g., Thompson et al. 2005; Parish et al. 2008; Rahn and Parish 2008) and act as nucleation sites for cloud droplets. These aerosols may play an important role in broadening the MBL cloud droplet distribution, as only a few
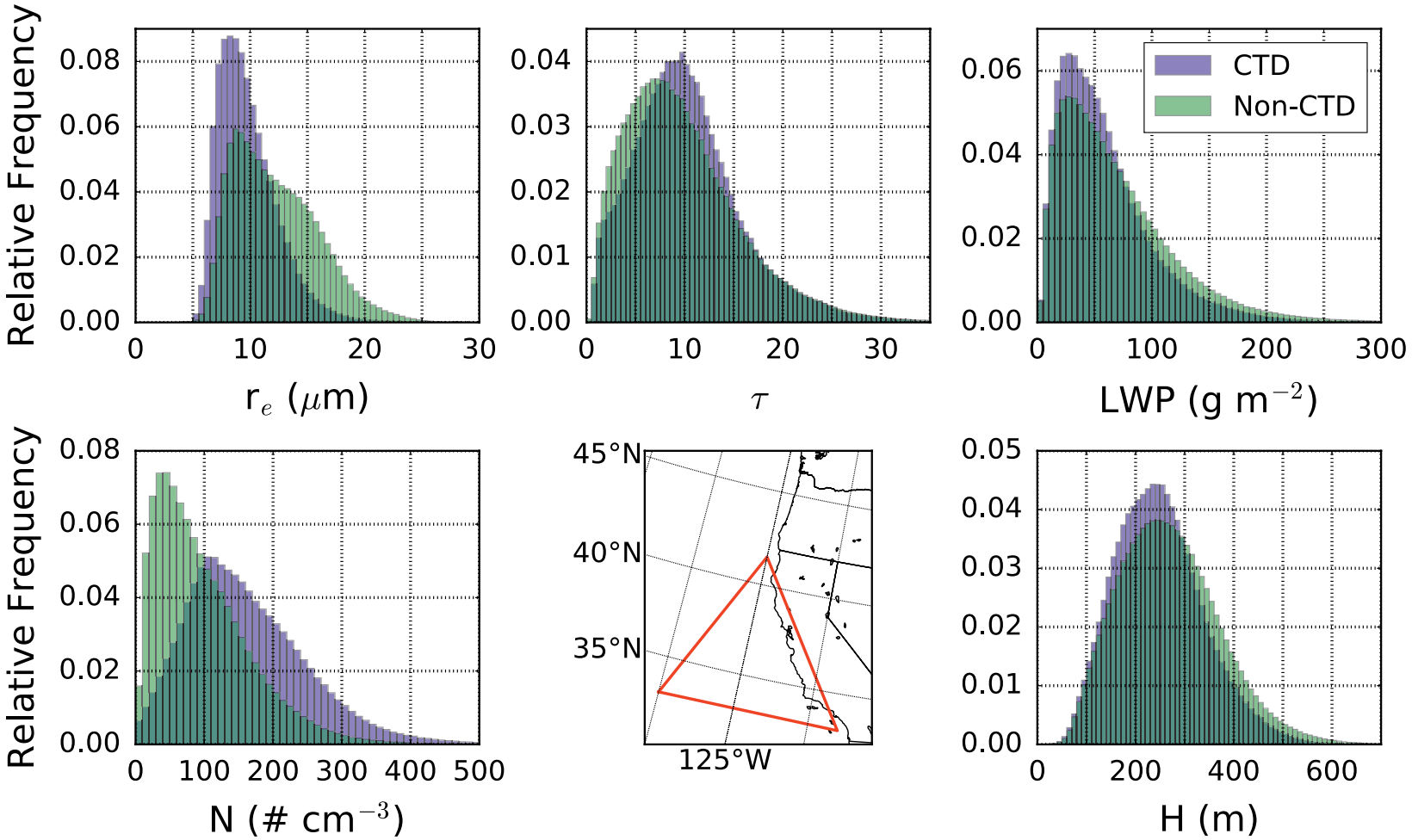

FIG. 6. Histograms comparing relative frequency of occurrence for the microphysical variables presented in Fig. 5 between CTD and non-CTD cases. The binned data are constrained to the outlined polygon (bottom middle panel) because this region approximates the spatial extent of a typical CTD. The histograms are mostly insensitive to the location, size, and shape of the polygon. 
giant cloud condensation nuclei (CCN) are needed to initiate drizzle even in clouds with relatively high CCN concentrations (Feingold et al. 1999; Jensen and Nugent 2017).

Dimethyl sulfide and, predominantly, ship exhaust contribute to the marine sulfate budget (e.g., Langley et al. 2010). While we have no reason to believe that shipping emissions differ between CTD and non-CTD cases, it is possible that CTD air parcels are more likely to interact with exhaust plumes prior to entering the cloud deck because they tend to follow shipping lanes (Fig. 8, bottom panel; e.g., see Fig. 9 in Coggon et al. 2012). In situ cloud samples from a CTD case considered here (27-28 July 2011; Coggon et al. 2012) reveal enhanced $N\left(>200 \mathrm{~cm}^{-3}\right)$ and high concentrations of vanadium, which is a primary by-product of ship exhaust (e.g., Agrawal et al. 2008).
The California coastal zone is home to a variety of aerosol that may be advected offshore (Fig. 8, bottom panel). Aircraft measurements suggest that biogenic volatile organic compounds, which are emitted by the heavily forested region in Northern California and southern Oregon, may make up a large portion of above-cloud aerosol (Coggon et al. 2014). Observations by Hegg et al. (2009) and Hegg et al. (2010) show that anywhere from about $50 \%$ to $67 \%$ of CCN offshore of California originate from anthropogenic sources. Due to agricultural activity, central and Southern California are large producers of mineral dust (e.g., Clausnitzer and Singer 1997; Ngo et al. 2010; Hand et al. 2017), which may act as CCN when coated by sea salt or sulfate (e.g., Levin et al. 2005; Gibson et al. 2007). Additionally, as drought risk in California continues to increase (e.g., Cook et al. 2015; Williams et al. 2015), the influence of
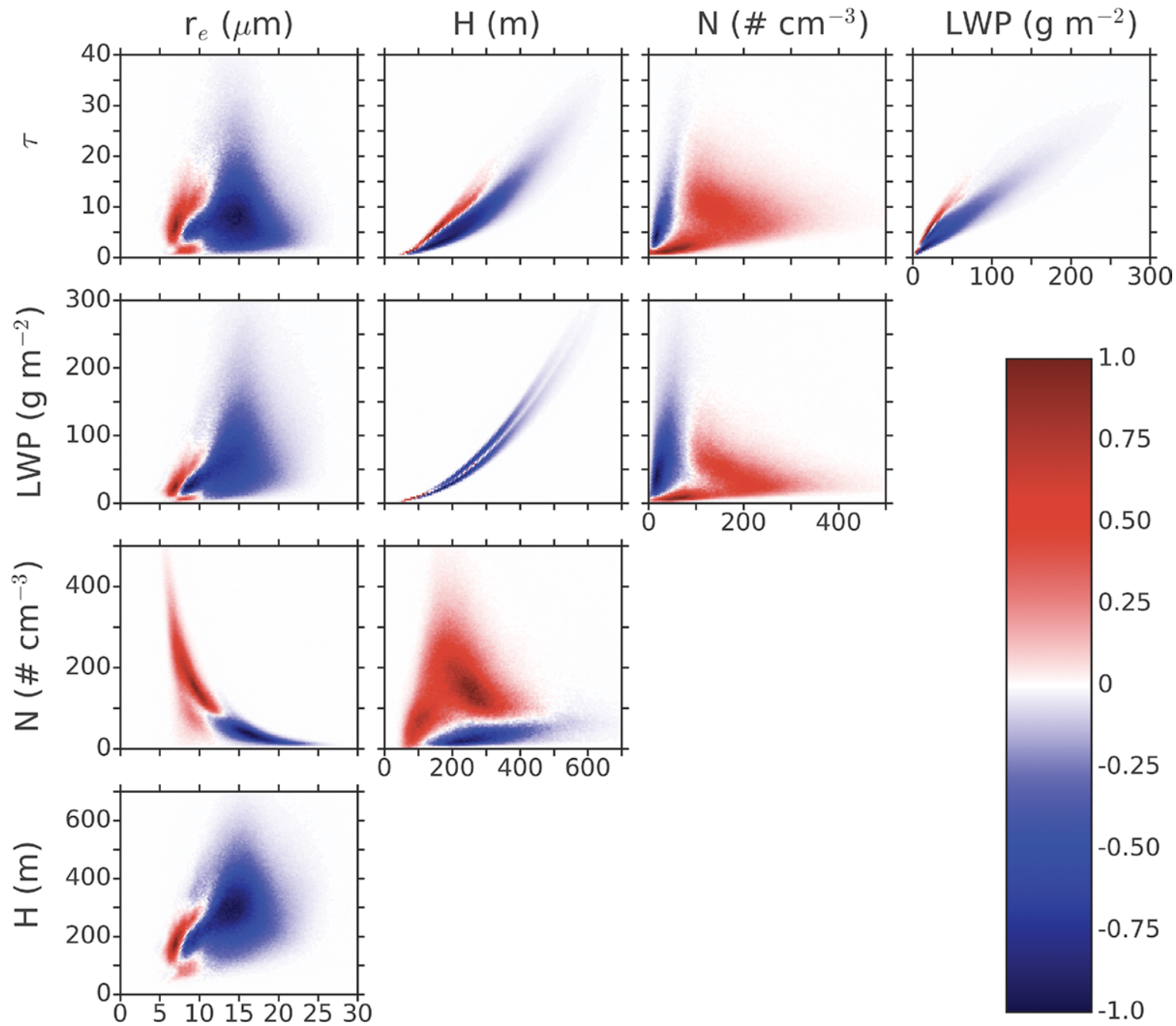

\section{0}
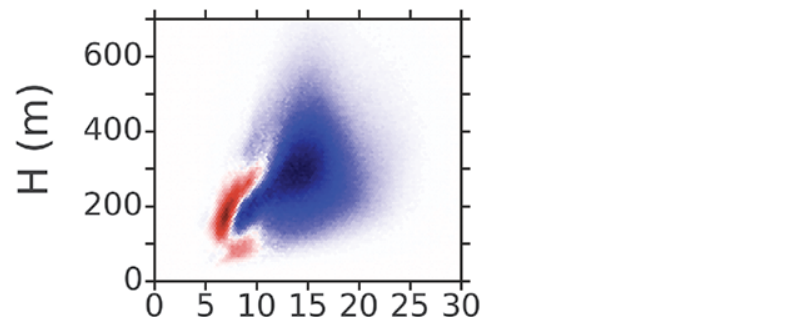

FIG. 7. Normalized joint probability density functions for the various microphysical parameter spaces presented in Fig. 5. Red (blue) color contours represent regions in the specified parameter space where the probability of finding a sample is higher (lower) in CTD cases compared to non-CTD cases. 
biomass burning aerosol on marine stratocumulus warrants additional research, as their radiative impact is profound (e.g., Brioude et al. 2009; Lu et al. 2018).

To address the extent to which CTDs may be influenced by these various anthropogenic sources, we generate composite backward trajectories for CTD and non-CTD cases (Fig. 9). The trajectories suggest that for both nearshore and offshore locations, CTD cloud decks are more susceptible to shipping and continental emission sources than non-CTD cloud decks. This finding is expected considering the large-scale meteorological changes that occur during CTD events to promote alongshore flow near the
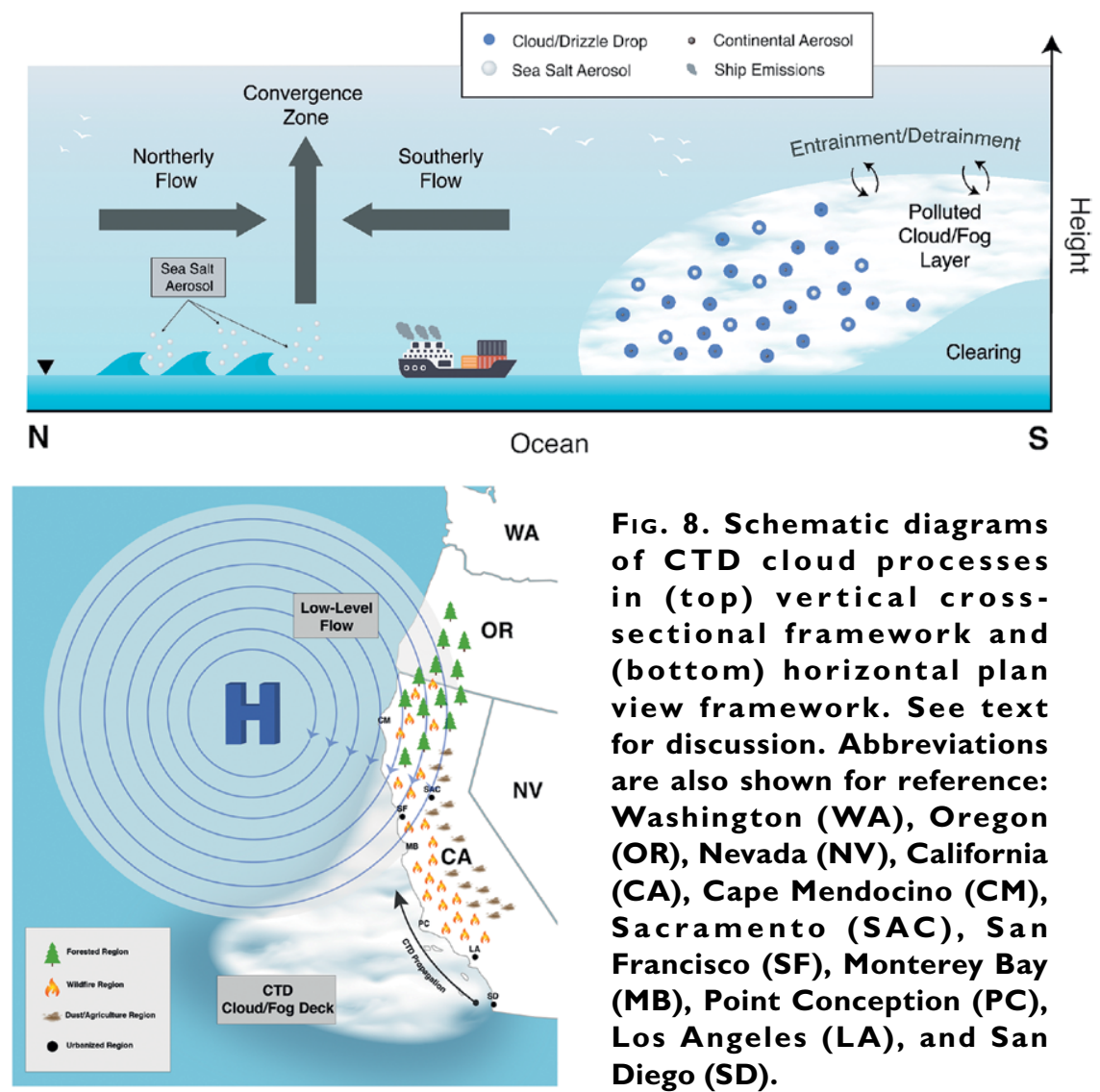

FIG. 8. Schematic diagrams of CTD cloud processes in (top) vertical crosssectional framework and (bottom) horizontal plan view framework. See text for discussion. Abbreviations are also shown for reference: Washington (WA), Oregon (OR), Nevada (NV), California (CA), Cape Mendocino (CM), Sacramento (SAC), San Francisco (SF), Monterey Bay (MB), Point Conception (PC), Los Angeles (LA), and San Diego (SD). surface and offshore flow above the MBL. Any lateral or vertical cloud entrainment will therefore allow polluted air parcels to mix into the cloud layer and alter cloud properties.

Using backward trajectories and data from the Cloud-Aerosol Lidar with Orthogonal Polarization (CALIOP) for an individual case study

FIG. 9. Composites of 72-h backward trajectories using $12-\mathrm{km}$ NAM grids in the Hybrid Single-Particle Lagrangian Integrated Trajectory (HYSPLIT) model beginning at (left) $39^{\circ} \mathrm{N}, 124^{\circ} \mathrm{W}$ and (right) $37^{\circ} \mathrm{N}, 124^{\circ} \mathrm{W}$ for (top) CTD and (bottom) non-CTD cases. Red, green, and blue lines represent trajectories ending at 100, 500, and $1,500 \mathrm{~m}$ AGL, respectively. Light, thin lines are shown for all trajectories while dark, bold lines represent mean trajectories. For each event, trajectories begin at 0000 UTC one day after the first dates listed in Tables I and 2. Grids are not available for two and seven of the CTD and non-CTD cases, respectively.
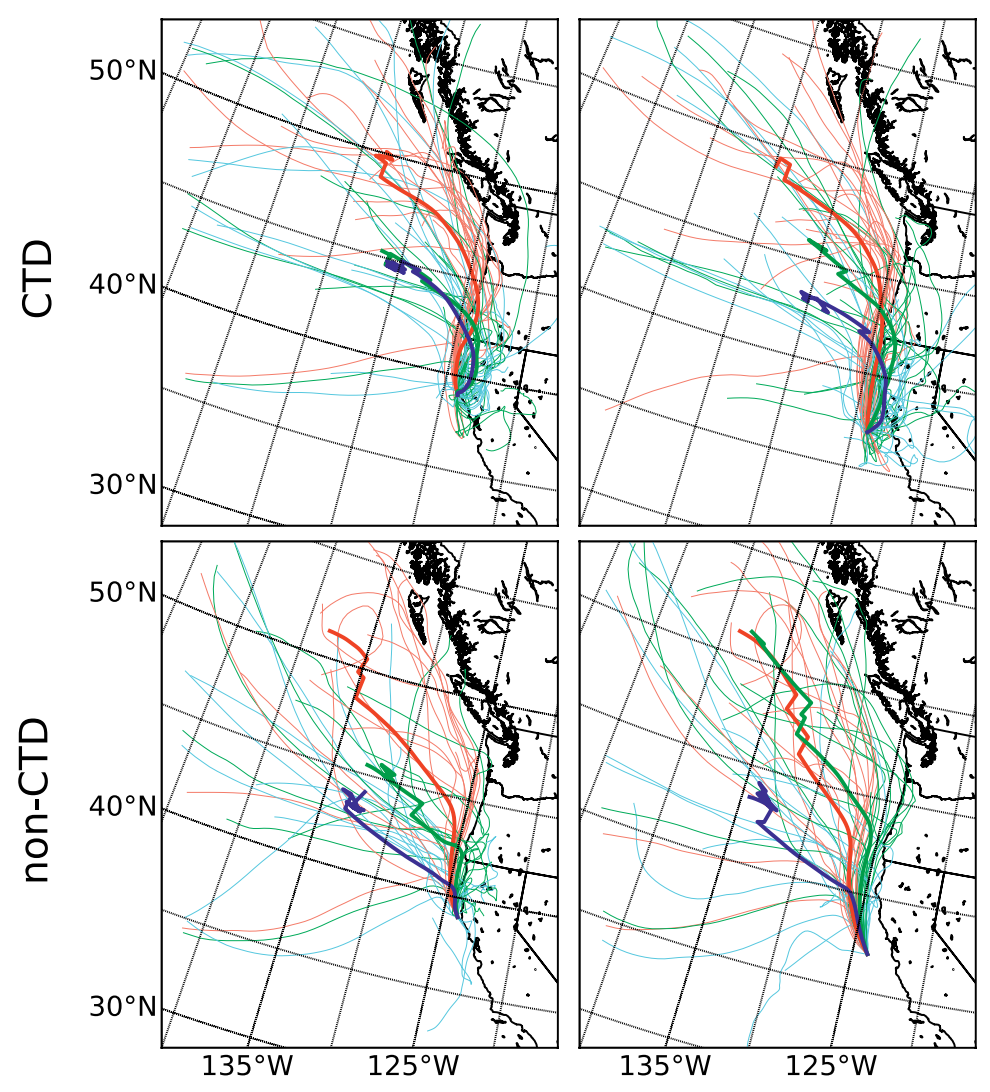
(9 July 2008), we show the numerous aerosol sources that may affect CTD clouds (Fig. 10). According to the CALIOP data, marine (sea salt), polluted continental (sulfate, nitrate, organic carbon, and ammonium mixed with urban pollution), and biomass burning (soot and organic carbon) aerosol are all present in the vicinity of the cloud deck. Any regions labeled as "other" indicate that a mixture of at least two aerosol types is present; therefore, it is likely that over the ocean the omnipresent sea salt aerosol often coexists with ship exhaust and/or various types of continental aerosol. A daytime Aqua MODIS "true color" image confirms that the smoke plumes on this day are from multiple wildfires in California. Examination of additional images from CALIOP (not shown) suggests that aerosol from both marine and continental sources are present in the vicinity of the cloud deck during each of the 23 CTD events.

\section{IMPLICATIONS FOR RADIATION}

BALANCE. Due to their anomalous properties, we expect marine clouds that accompany CTDs to affect the radiation balance differently than non-CTD marine clouds over the northeast Pacific Ocean. We compare fractional cloud albedo $\alpha_{c}$ for CTD and non-CTD cases through frequency distributions in Fig. 11. Unsurprisingly, due to the large difference between cloud and ocean albedos, both regimes exhibit a strong SW cloud radiative forcing $\left(\mathrm{CRF}_{\mathrm{SW}}\right)$, or cooling effect (see sidebar "Shortwave cloud radiative forcing"). The mean values for $\alpha_{c}$ and $\mathrm{CRF}_{\mathrm{SW}}$ are $53.5 \%$ and $-148.9 \mathrm{~W} \mathrm{~m}^{-2}\left(51.6 \%\right.$ and $\left.-142.5 \mathrm{~W} \mathrm{~m}^{-2}\right)$ for CTD (non-CTD) cases, respectively. The histograms show more cases of high $\alpha_{c}$ during CTDs; thus, on average, these clouds reflect more incoming shortwave radiation than their non-CTD counterparts. We attribute the $\sim 2 \%$ albedo increase to the enhancement of droplet concentration and subsequent increase (decrease) in CTD optical depth (droplet size). In situ observations that compare a CTD event to two non-CTD events also show that CTD clouds have relatively high $\tau$ (14.9 vs 10.2 and 7.6), low $r_{e}(8.9 \mu \mathrm{m}$ vs 9.2 and $14.3 \mu \mathrm{m})$, and high $\alpha_{c}(63 \%$ vs $59 \%$ and $48 \%)$ values (Crosbie et al. 2016).

Assuming the longwave radiative forcing of the two cloud regimes is equal, results suggest that, on average, marine stratiform CTD clouds off the coast of California exert a top-of-the-atmosphere (TOA) SW radiative forcing of $\sim 4 \%\left(\sim 6.4 \mathrm{~W} \mathrm{~m}^{-2}\right)$ more than non-CTD clouds. We emphasize that CTD clouds are present less frequently than marine stratiform clouds that form under typical summertime conditions. Moreover, the cloud clearing that usually occurs prior to the arrival of a CTD also has implications for the
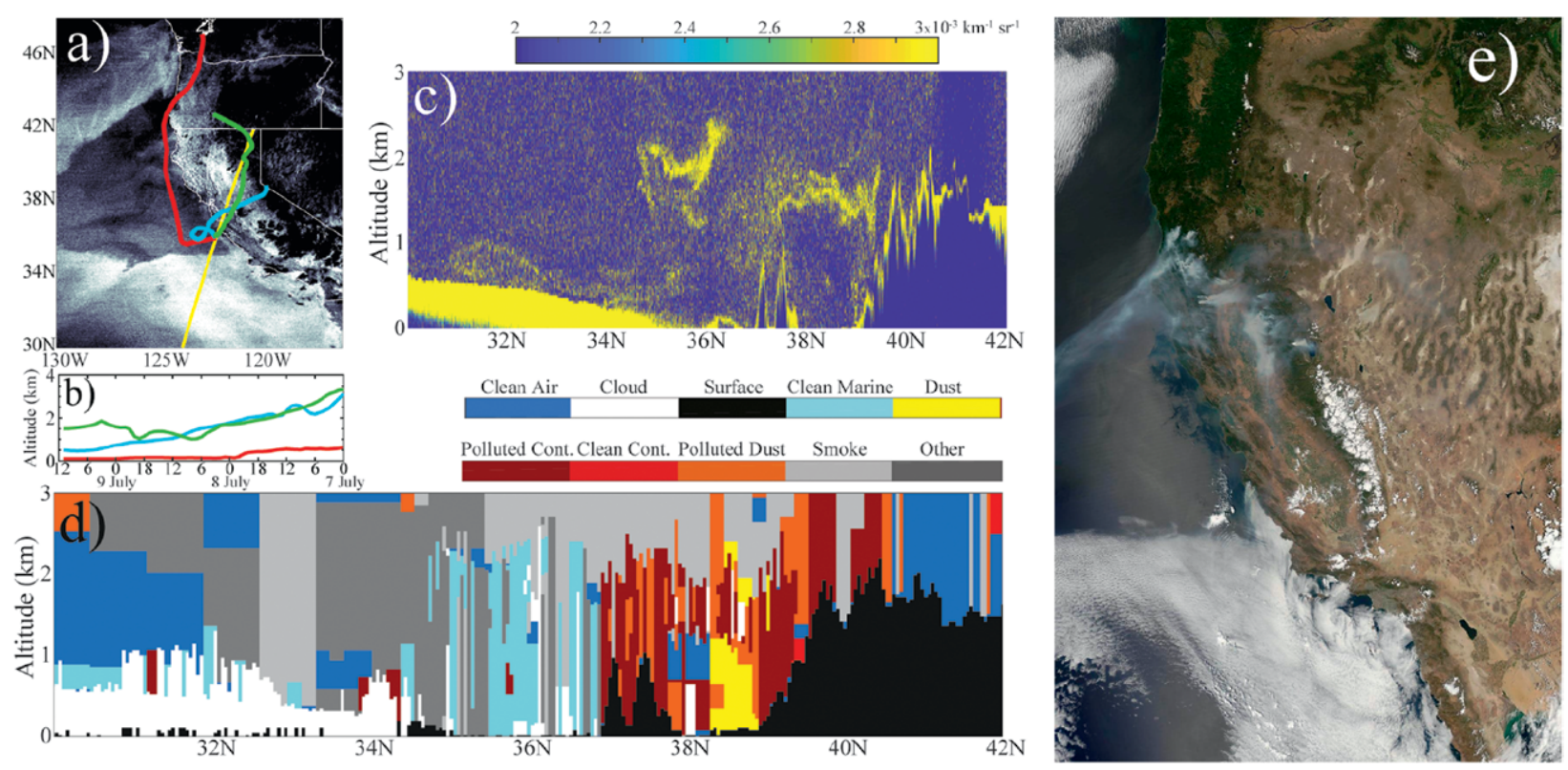

Fig. 10. (a) The 1000 UTC 9 Jul 2008 GOES fog product using band 4 (10.7 $\mu \mathrm{m})$ minus band $2(3.9 \mu \mathrm{m})$, the 1013-1020 UTC Cloud-Aerosol Lidar and Infrared Pathfinder Satellite Observations (CALIPSO) overpass used for cross sections (yellow), and the 1000 UTC HYSPLIT backward trajectories at $100 \mathrm{~m}$ (red), $500 \mathrm{~m}$ (blue), and I,500 m (green) for $36^{\circ} \mathrm{N}, 122.2^{\circ} \mathrm{W}$. (b) Time-height plot of backward trajectories. (c) Cross section of 532-nm total attenuated backscatter (units in $\mathrm{km}^{-1} \mathrm{sr}^{-1}$ ). (d) Cross section of CALIOP vertical feature mask including aerosol feature subtypes and corresponding legend. (e) A 9 Jul 2008 daytime Aqua MODIS "true color" image. 
radiation balance (i.e., relatively less reflected SW).

\section{SUMMARY AND FUTURE WORK.}

Through the use of various observational tools, we provide a new perspective on the disruption of the familiar summertime marine stratiform deck offshore California. It is shown that MBL clouds which form under the typical northerly flow conditions (non-CTD) differ notably compared to those which form under the anomalous southerly flow conditions (CTD). The main characteristics differentiating these two cloud regimes are summarized in Table 4.

In the context of CTDs, the interplay between aerosol and clouds is clearly a complex issue that must be further addressed. Research pertaining to individual aspects of the aforementioned aerosol sources is ongoing; untangling the symbiotic relationships between these aerosols is not trivial. Although we do not present here any direct observational evidence regarding the composition of particles acting as $\mathrm{CCN}$, we confidently hypothesize that the enhancement of $N$ is primarily due to an abundance of hygroscopic aerosols originating from both continental and oceanic sources. The degree to which these aerosols are successful in their competition to become activation sites and contribute toward subsequent cloud processes (e.g., diffusional growth, autoconversion, collisioncoalescence) is a question that remains unanswered.

It is evident that the large-scale meteorological conditions strongly influence the occurrence of a CTD. A first step is to understand better the frequency of CTD events, in addition to the specific synoptic-scale pattern(s) that affect particular aspects of the CTD life cycle. For instance, how do global cycles, such as the El Niño-Southern Oscillation and Pacific decadal oscillation, affect the shift in the Pacific high during the boreal summer? Moreover, it may be informative to identify any clear differences in the large-scale conditions (e.g., strength and location of offshore continental flow) that support weak versus strong CTDs because they may differ in terms of propagation speed, cloud properties, and lifetime. Unsupervised machine learning techniques, such as self-organizing maps, are sometimes applied to extensive datasets in atmospheric science (e.g., Liu and Weisberg 2011). Employing

where $S_{0}$ is the solar constant, and $\alpha_{0}$ is ocean albedo. We assume $S_{0}=1,370 \mathrm{~W} \mathrm{~m}^{-2}$ and $\alpha_{0}=0.10(10 \%)$. Because the albedo of marine stratiform clouds is much greater than $10 \%$, we expect $\mathrm{CRF}_{s \mathrm{~W}}$ to be large and negative. 
TABLE 4. Summary of main differences between non-CTD and CTD features.

\begin{tabular}{|lll|}
\hline Feature & Non-CTD & CTD \\
\hline Pacific high & $\begin{array}{l}\text { Relatively weak and located far } \\
\text { offshore }\end{array}$ & $\begin{array}{l}\text { Relatively strong and located closer to Pacific } \\
\text { Northwest }\end{array}$ \\
\hline $\begin{array}{l}\text { Alongshore pressure } \\
\text { gradient force }\end{array}$ & Directed southward everywhere & $\begin{array}{l}\text { Directed southward (northward) north (south) of } \\
\text { central California }\end{array}$ \\
\hline Near-surface winds & Northerly flow everywhere & Northerly (southerly) flow outside (inside) CTD \\
\hline SSTs & $\begin{array}{l}\text { Persistent upwelling regime } \\
\text { leading to relatively cool SSTs }\end{array}$ & $\begin{array}{l}\text { Three-stage cycle of relatively weak-strong-weak } \\
\text { winds leading to relatively warm-cool-warm SSTs }\end{array}$ \\
\hline Microphysical properties & Relatively low $N$ and large $r_{\mathrm{e}}$ & Relatively high $N$ and small $r_{\mathrm{e}}$ \\
\hline Aerosol influences & $\begin{array}{l}\text { Primarily marine sources } \\
\text { (sea salt and ship exhaust) }\end{array}$ & $\begin{array}{l}\text { Both marine sources and continental sources } \\
\text { (forested, wildfire, agricultural, and urbanized regions) }\end{array}$ \\
\hline Radiative impact & $\begin{array}{l}\text { Relatively low albedo and less } \\
\text { reflected SW }\end{array}$ & Relatively high albedo and more reflected SW \\
\hline
\end{tabular}

these techniques to CTDs may yield important details regarding the physical connection between predictive variables and ultimately lead to higher-accuracy forecasts across a range of temporal and spatial scales.

Observations (e.g., Minnis et al. 1992; Painemal et al. 2013; Burleyson et al. 2013) and idealized largeeddy simulations (e.g., Caldwell et al. 2005; Caldwell and Bretherton 2009; Kazil et al. 2016) show that marine stratocumulus display notable diurnal variability in, for example, $H$, LWP, entrainment rate, and drizzle production. Capturing the midmorning and early evening transition periods in a numerical model is critical for the cloud field evolution (e.g., horizontal and vertical distribution of liquid water and the subsequent impact on drizzle processes) and continues to challenge both the regional forecasting and climate prediction communities. One way to potentially ameliorate forecasting errors associated with coastal marine cloud-radiation interactions is to collocate aircraft (top-down) and surface-based (bottom-up) measurements (e.g., microwave radiometer).

In general, the diurnal variability in MBL cloud properties is difficult to analyze using satellite retrievals because most techniques utilize solar wavelengths and are limited to daylight hours. The Visible Infrared Imaging Radiometer Suite (VIIRS) Day/Night Band, however, is a unique sensor that can be utilized to detect marine stratocumulus clouds at night (e.g., Miller et al. 2013; Seaman and Miller 2015). Additionally, future efforts should exploit the new channels aboard the Geostationary Operational Environmental Satellite system (GOES-R) that can retrieve aerosol and cloud properties while coordinating field campaigns to validate these remote sensing capabilities.

Additional observations, specifically in situ, are needed to confirm the remote sensing Aqua MODIS observations shown here that suggest CTD clouds and fogs are composed of more cloud droplets than typical marine stratiform clouds. In situ measurements should include instruments that are capable of characterizing the chemical composition of aerosol. Aerosol size distribution measurements focusing on sea salt are necessary to determine the potential impact on drizzle processes. Because CTD clouds typically extend to near the ocean surface, accurately measuring aerosol below cloud base is very challenging. Therefore, utilizing platforms such as unmanned aerial vehicles seems appealing, especially as momentous advances continue in their deployment for atmospheric, and specifically air quality, observations (e.g., Villa et al. 2016).

CTDs should also be probed through high-resolution numerical modeling methods. Sensitivity studies using a framework such as the Weather Research and Forecasting Model (Skamarock et al. 2008) may allow for a deeper understanding of cloud processes relevant to CTDs. Once the model accurately represents the horizontal and vertical distributions of cloud liquid water using a sensible combination of physical parameterizations, then various components may be perturbed to yield additional insight into small-scale atmospheric processes. Furthermore, recent modeling efforts targeting more detailed microphysical treatments [e.g., prognostic supersaturation using the predicted particle properties (P3) scheme (Morrison and Milbrandt 2015) and prognostic aerosol using the Thompson aerosolaware scheme (Thompson and Eidhammer 2014)] may prove useful when examining CTDs. Ultimately, because the real-life problem is a complicated interaction between multiple systems (ocean, land, and atmosphere), running a fully coupled model is the most ideal technique to represent CTD systems. 
ACKNOWLEDGMENTS. Author TWJ is supported in part by the National Science Foundation through Grant AGS-1439594 and by the State of Wyoming. Author ZJL thanks support through the Department of Energy from Grant DE-SC0016354. Author DAR is supported in part by the National Science Foundation through Grant AGS1439515. We gratefully thank Justine Sulia for creating the schematics. We also thank the three anonymous reviewers and the editor whose comments have improved the manuscript. Steven Platnick provided helpful information regarding the Aqua MODIS data processing. The MODIS "true color" image (Fig. 10e) is courtesy of the Space Science and Engineering Center at the University of Wisconsin-Madison.

\section{REFERENCES}

Agrawal, H., Q. G. J. Malloy, W. A. Welch, J. W. Miller, and D. R. Crocker III, 2008: In-use gaseous and particulate matter emissions from a modern ocean going container vessel. Atmos. Environ., 42, 5504-5510, https://doi.org/10.1016/j.atmosenv.2008.02.053.

Albrecht, B. A., 1989: Aerosols, cloud microphysics, and fractional cloudiness. Science, 245, 1227-1230, https://doi.org/10.1126/science.245.4923.1227.

Bachiochi, D. R., and T. N. Krishnamurti, 2000: Enhanced low-level stratus in the FSU coupled oceanatmosphere model. Mon. Wea. Rev., 128, 3083-3103, https://doi.org/10.1175/1520-0493(2000)128<3083: ELLSIT>2.0.CO;2.

Banta, R. M., L. D. Olivier, and D. H. Levinson, 1993: Evolution of the Monterey Bay sea-breeze layer as observed by pulsed Doppler lidar. J. Atmos. Sci., 50, 3959-3982, https://doi.org/10.1175/1520 -0469(1993)050<3959:EOTMBS>2.0.CO;2.

Beardsley, R. C., C. E. Dorman, C. A. Friehe, L. K. Rosenfeld, and C. D. Winant, 1987: Local atmospheric forcing during the Coastal Ocean Dynamics Experiment: 1. A description of the marine boundary layer and atmospheric conditions over a northern California upwelling region. J. Geophys. Res., 92, 1467-1488, https://doi.org/10.1029/JC092iC02p01467.

Bennartz, R., 2007: Global assessment of marine boundary layer cloud droplet number concentration from satellite. J. Geophys. Res., 112, D02201, https://doi .org/10.1029/2006JD007547.

— of warm cloud droplet number concentration based on 13 years of AQUA-MODIS observations. Atmos. Chem. Phys., 17, 9815-9836, https://doi.org/10.5194 /acp-17-9815-2017.

Bond, N. A., C. F. Mass, and J. E. Overland, 1996: Coastally trapped wind reversals along the United
States West Coast during the warm season. Part I: Climatology and temporal evolution. Mon. Wea. Rev., 124, 430-445, https://doi.org/10.1175/1520 -0493(1996)124<0430:CTWRAT>2.0.CO;2.

Bony, S., and J.-L. Dufresne, 2005: Marine boundary layer clouds at the heart of tropical cloud feedback uncertainties in climate models. Geophys. Res. Lett., 32, L20806, https://doi.org/10.1029/2005GL023851.

Boucher, O., and Coauthors, 2013: Clouds and aerosols. Climate Change 2013: The Physical Science Basis, T. F. Stocker et al., Eds., Cambridge University Press, 571-657.

Brenguier, J. L., and Coauthors, 2000: An overview of the ACE-2 CLOUDYCOLUMN closure experiment. Tellus, 52B, 815-827, https://doi.org/10.1034/j.1600 $-0889.2000 .00047 . x$.

Brioude, J., and Coauthors, 2009: Effect of biomass burning on marine stratocumulus clouds off the California coast. Atmos. Chem. Phys., 9, 8841-8856, https://doi.org/10.5194/acp-9-8841-2009.

Burleyson, C. D., S. P. de Szoeke, S. E. Yuter, M. Wilbanks, and W. A. Brewer, 2013: Ship-based observations of the diurnal cycle of southeast Pacific marine stratocumulus clouds and precipitation. J. Atmos. Sci., 70, 3876-3894, https://doi.org/10.1175 /JAS-D-13-01.1.

Caldwell, P., and C. S. Bretherton, 2009: Large eddy simulation of the diurnal cycle in Southeast Pacific stratocumulus. J. Atmos. Sci., 66, 432-449, https:// doi.org/10.1175/2008JAS2785.1.

— C. S. Bretherton, and R. Wood, 2005: Mixed-layer budget analysis of the diurnal cycle of entrainment in Southeast Pacific stratocumulus. J. Atmos. Sci., 62, 3775-3791, https://doi.org/10.1175/JAS3561.1.

Clausnitzer, H., and M. Singer, 1997: Intensive land preparation emits respirable dust. Calif. Agric., 51, 27-30, https://doi.org/10.3733/ca.v051n02p27.

Coggon, M. M., and Coauthors, 2012: Ship impacts on the marine atmosphere: Insights into the contribution of shipping emissions to the properties of marine aerosol and clouds. Atmos. Chem. Phys., 12, 84398458, https://doi.org/10.5194/acp-12-8439-2012.

_ biogenic impacts on marine aerosol and clouds off the coast of California. J. Geophys. Res. Atmos., 119, 6724-6748, https://doi.org/10.1002/2013JD021228.

Cook, B. I., T. R. Ault, and J. E. Smerdon, 2015: Unprecedented 21st century drought risk in the American Southwest and Central Plains. Sci. Adv., 1, e1400082, https://doi.org/10.1126/sciadv.1400082.

Crosbie, E., and Coauthors, 2016: Stratocumulus cloud clearings and notable thermodynamic and aerosol contrasts across the clear-cloudy interface. $J$. 
Atmos. Sci., 73, 1083-1099, https://doi.org/10.1175 /JAS-D-15-0137.1.

Delecluse, P., M. K. Davey, Y. Kitamura, S. G. H. Philander, M. Suarez, and L. Bengtsson, 1998: Coupled general circulation modeling of the tropical Pacific. J. Geophys. Res., 103, 14357-14373, https:// doi.org/10.1029/97JC02546.

Dorman, C. E., 1985: Evidence of Kelvin waves in California's marine layer and related eddy generation. Mon. Wea. Rev., 113, 827-839, https://doi.org/10.1175 /1520-0493(1985)113<0827:EOKWIC>2.0.CO;2.

Feingold, G., W. R. Cotton, S. M. Kreidenweis, and J. T. Davis, 1999: The impact of giant cloud condensation nuclei on drizzle formation in stratocumulus: Implications for cloud radiative properties. J. Atmos. Sci., 56, 4100-4117, https://doi.org/10.1175/1520 -0469(1999)056<4100:TIOGCC>2.0.CO;2.

Feng, L., H. Shen, Y. Zhu, H. Gao, and X. Yao, 2017: Insight into generation and evolution of sea-salt aerosols from field measurements in diversified marine and coastal atmospheres. Sci. Rep., 7, 41260, https:// doi.org/10.1038/srep41260.

Fewings, M. R., L. Washburn, C. E. Dorman, C. Gotschalk, and K. Lombardo, 2016: Synoptic forcing of wind relaxations at Pt. Conception, California. J. Geophys. Res. Oceans, 121, 5711-5730, https://doi .org/10.1002/2016JC011699.

Flynn, K. R., M. R. Fewings, C. Gotschalk, and K. Lombardo, 2017: Large-scale anomalies in seasurface temperature and air-sea fluxes during wind relaxation events off the United States West Coast in summer. J. Geophys. Res. Oceans, 122, 2574-2594, https://doi.org/10.1002/2016JC012613.

Garreaud, R., and J. Rutllant, 2003: Coastal lows along the subtropical west coast of South America: Numerical simulation of a typical case. Mon. Wea. Rev., 131, 891-908, https://doi.org/10.1175/1520 -0493(2003)131<0891:CLATSW>2.0.CO;2.

—, J. A. Rutllant, and H. Fuenzalida, 2002: Coastal lows along the subtropical west coast of South America: Mean structure and evolution. Mon. Wea. Rev., 130, 75-88, https://doi.org/10.1175/1520 -0493(2002)130<0075:CLATSW>2.0.CO;2.

Gibson, R. E., K. M. Gierlus, P. K. Hudson, and V. H. Grassin, 2007: Generation of internally mixed insoluble and soluble aerosol particles to investigate the impact of atmospheric aging and heterogeneous processing on the CCN activity of mineral dust aerosol. Aerosol Sci. Technol., 41, 914-924, https:// doi.org/10.1080/02786820701557222.

Gill, A. E., 1977: Coastally trapped waves in the atmosphere. Quart. J. Roy. Meteor. Soc., 103, 431-440, https://doi.org/10.1002/qj.49710343704.
Goela, P. C., C. Cordeiro, S. Danchenko, J. Icely, S. Cristina, and A. Newton, 2016: Time series analysis of data for sea surface temperature and upwelling components from the southwest coast of Portugal. J. Mar. Syst., 163, 12-22, https://doi.org/10.1016/j .jmarsys.2016.06.002.

Gong, S. L., 2003: A parameterization of sea-salt aerosol source function for sub- and super-micron particles. Global Biogeochem. Cycles, 17, 1097, https://doi .org/10.1029/2003GB002079.

—, L. A. Barrie, and J.-P. Blanchet, 1997: Modeling sea-salt aerosols in the atmosphere: 1 . model development. J. Geophys. Res., 102, 3805-3818, https://doi .org/10.1029/96JD02953.

Haack, T., S. D. Burk, C. Dorman, and D. Rogers, 2001: Supercritical flow interaction within the Cape Blanco-Cape Mendocino orographic complex. Mon. Wea. Rev., 129, 688-708, https://doi .org/10.1175/1520-0493(2001)129<0688:SFIWTC $>2.0 . \mathrm{CO} ; 2$.

Hand, J. L., T. E. Gill, and B. A. Schichtel, 2017: Spatial and seasonal variability in fine mineral dust and coarse aerosol mass at remote sites across the United States. J. Geophys. Res. Atmos., 122, 3080-3097, https://doi.org/10.1002/2016JD026290.

Hartmann, D. L., M. E. Ockert-Bell, and M. L. Michelsen, 1992: The effect of cloud type on Earth's energy balance: Global analysis. J. Climate, 5, 1281-1304, https://doi.org/10.1175/1520-0442(1992)005<1281: TEOCTO $>2.0 . \mathrm{CO} ; 2$.

Hegg, D. A., D. S. Covert, H. H. Jonsson, and R. Woods, 2009: Differentiating natural and anthropogenic cloud condensation nuclei in the California coastal zone. Tellus, 61B, 669-676, https://doi.org/10.1111 /j.1600-0889.2009.00435.x.

- D. S. Covert, H. H. Jonsson, and R. K. Woods, 2010: The contribution of anthropogenic aerosols to aerosol light-scattering and CCN activity in the California coastal zone. Atmos. Chem. Phys., 10, 7341-7351, https://doi.org/10.5194/acp-10-7341 -2010 .

Holland, G. J., and L. M. Leslie, 1986: Ducted coastal ridging over S.E. Australia. Quart. J. Roy. Meteor. Soc., 112, 731-748, https://doi.org/10.1002/qj.49711247310. Iacobellis, S. F., and D. R. Cayan, 2013: The variability of California summertime marine stratus: Impacts on surface air temperatures. J. Geophys. Res. Atmos., 118, 9105-9122, https://doi.org/10.1002/jgrd.50652.

Jaeglé, L., P. K. Quinn, T. S. Bates, B. Alexander, and J.-T. Lin, 2011: Global distribution of sea salt aerosols: New constraints from in situ and remote sensing observations. Atmos. Chem. Phys., 11, 3137-3157, https://doi.org/10.5194/acp-11-3137-2011. 
Jensen, J. B., and A. D. Nugent, 2017: Condensational growth of drops formed on giant sea-salt aerosol particles. J. Atmos. Sci., 74, 679-697, https://doi .org/10.1175/JAS-D-15-0370.1.

Jiang, X., T. L. Kubar, S. Wong, W. S. Olson, and D. E. Waliser, 2014: Modulation of marine low clouds associated with the tropical intraseasonal variability over the eastern Pacific. J. Climate, 27, 5560-5574, https://doi.org/10.1175/JCLI-D-13-00569.1.

Juliano, T. W., T. R. Parish, D. A. Rahn, and D. C. Leon, 2017: An atmospheric hydraulic jump in the Santa Barbara Channel. J. Appl. Meteor. Climatol., 56, 2981-2998, https://doi.org/10.1175/JAMC-D $-16-0396.1$.

Kazil, J., G. Feingold, and T. Yamaguchi, 2016: Wind speed response of marine non-precipitating stratocumulus clouds over a diurnal cycle in cloud-system resolving simulations. Atmos. Chem. Phys., 16, 5811-5839, https://doi.org/10.5194/acp-16-5811-2016.

Klein, S. A., and D. L. Hartmann, 1993: The seasonal cycle of low stratiform clouds. J. Climate, 6, 1587-1606, https://doi.org/10.1175/1520-0442(1993)006<1587: TSCOLS $>2.0 . \mathrm{CO} ; 2$.

Kloesel, K. A., 1992: Marine stratocumulus cloud clearing episodes observed during FIRE. Mon. Wea. Rev., 120, 565-578, https://doi.org/10.1175/1520 -0493(1992)120<0565:MSCCEO>2.0.CO;2.

Koraĉin, D., and C. E. Dorman, Eds., 2017: Marine Fog: Challenges and Advancements in Observations, Modeling, and Forecasting. Springer, 537 pp.

Lacis, A. A., and J. E. Hansen, 1974: A parameterization for the absorption of solar radiation in the Earth's atmosphere. J. Atmos. Sci., 31, 118-133, https://doi .org/10.1175/1520-0469(1974)031<0118:APFTAO $>2.0 . \mathrm{CO} ; 2$.

Langley, L., W. R. Leaitch, U. Lohmann, N. C. Shantz, and D. R. Worsnop, 2010: Contributions from DMS and ship emissions to CCN observed over the summertime North Pacific. Atmos. Chem. Phys., 10, 1287-1314, https://doi.org/10.5194/acp-10-1287 -2010 .

Levin, Z., A. Teller, E. Ganor, and Y. Yin, 2005: On the interactions of mineral dust, sea-salt particles, and clouds: A measurement and modeling study from the Mediterranean Israeli Dust Experiment campaign. J. Geophys. Res., 110, D20202, https://doi .org/10.1029/2005JD005810.

Liu, Y., and R. H. Weisberg, 2011: A review of selforganizing map applications in meteorology and oceanography. Self Organizing Maps-Applications and Novel Algorithm Design, InTech, 253-272.

Lovett, R. F., 1978: Quantitative measurement of airborne sea-salt in the North Atlantic. Tellus,
30, 358-364, https://doi.org/10.3402/tellusa.v30i4 .10354 .

Lu, M.-L., and J. H. Seinfeld, 2006: Effect of aerosol number concentration on cloud droplet dispersion: A large-eddy simulation study and implications for aerosol indirect forcing. J. Geophys. Res., 111, D02207, https://doi.org/10.1029/2005JD006419.

Lu, Z., and Coauthors, 2018: Biomass smoke from southern Africa can significantly enhance the brightness of stratocumulus over the southeastern Atlantic Ocean. Proc. Natl. Acad. Sci. USA, 115, 2924-2929, https://doi.org/10.1073/pnas.1713703115.

Mass, C. F., and M. D. Albright, 1987: Coastal southerlies and alongshore surges of the West Coast of North America: Evidence of mesoscale topographically trapped response to synoptic forcing. Mon. Wea. Rev., 115, 1707-1738, https://doi.org/10.1175/1520 -0493(1987)115<1707:CSAASO >2.0.CO;2.

— reversals along the United States West Coast during the warm season. Part II: Synoptic evolution. Mon. Wea. Rev., 124, 446-461, https://doi.org/10.1175/1520 -0493(1996)124<0446:CTWRAT>2.0.CO;2.

Melton, C., L. Washburn, and C. Gotschalk, 2009: Wind relaxations and poleward flow events in a coastal upwelling system on the central California coast. J. Geophys. Res., 114, C11016, https://doi .org/10.1029/2009JC005397.

Miller, D. J., Z. Zhang, A. S. Ackerman, S. Platnick, and B. A. Baum, 2016: The impact of cloud vertical profile on liquid water path retrieval based on the bispectral method: A theoretical study based on large-eddy simulations of shallow marine boundary layer clouds. J. Geophys. Res. Atmos., 121, 4122-4141, https://doi.org/10.1002/2015JD024322.

Miller, S. D., and Coauthors, 2013: Illuminating the capabilities of the Suomi National Polar-Orbiting Partnership (NPP) Visible Infrared Imaging Radiometer Suite (VIIRS) Day/Night Band. Remote Sens. 5, 6717-6766, https://doi.org/10.3390/rs5126717.

Minnis, P., P. W. Heck, D. F. Young, C. W. Fairall, and J. B. Snider, 1992: Stratocumulus cloud properties derived from simultaneous satellite and island-based instrumentation during FIRE. J. Appl. Meteor., 31, 317-339, https://doi.org/10.1175/1520 -0450(1992)031<0317:SCPDFS>2.0.CO;2.

Morrison, H., and J. A. Milbrandt, 2015: Parameterization of cloud microphysics based on the prediction of bulk ice particle properties. Part I: Scheme description and idealized tests. J. Atmos. Sci., 72, 287-311, https://doi.org/10.1175/JAS-D-14-0065.1.

Nakajima, T., and M. D. King, 1990: Determination of the optical thickness and effective particle radius of 
clouds from reflected solar radiation measurements. Part I: Theory. J. Atmos. Sci., 47, 1878-1893, https:// doi.org/10.1175/1520-0469(1990)047<1878:DOTOTA $>2.0 . \mathrm{CO} ; 2$.

Ngo, M. A., and Coauthors, 2010: Airborne particles in the San Joaquin Valley may affect human health. Calif. Agric., 64, 12-16, https://doi.org/10.3733/ca.v064n01p12.

Nuss, W. A., and Coauthors, 2000: Coastally trapped wind reversals: Progress toward understanding. Bull. Amer. Meteor. Soc., 81, 719-743, https://doi.org/10.1175 /1520-0477(2000)081<0719:CTWRPT>2.3.CO;2.

Painemal, D., P. Minnis, and L. O'Neill, 2013: The diurnal cycle of cloud-top height and cloud cover over the southeastern Pacific as observed by GOES-10. J. Atmos. Sci., 70, 2393-2408, https://doi.org/10.1175 /JAS-D-12-0325.1.

Palmer, T. N., and D. L. T. Anderson, 1994: The prospect for seasonal forecasting-A review paper. Quart. J. Roy. Meteor. Soc., 120, 755-793, https://doi .org/10.1002/qj.49712051802.

Parish, T. R., 2000: Forcing of the summertime low-level jet along the California coast. J. Appl. Meteor., 39, 2421-2433, https://doi.org/10.1175/1520 -0450(2000)039<2421:FOTSLL>2.0.CO;2.

- D. A. Rahn, and D. Leon, 2008: Aircraft observations of a coastally trapped wind reversal off the California coast. Mon. Wea. Rev., 136, 644-663, https://doi.org/10.1175/2007MWR2199.1.

Pierce, J. R., and P. J. Adams, 2006: Global evaluation of CCN formation by direct emission of sea salt and growth of ultrafine sea salt. J. Geophys. Res., 111, D06203, https://doi.org/10.1029/2005JD006186.

Platnick, S., 2000: Vertical photon transport in cloud remote sensing problems. J. Geophys. Res., 105, 22919 22 935, https://doi.org/10.1029/2000JD900333.

Rahn, D. A., and T. R. Parish, 2008: A study of the forcing of the 22-25 June 2006 coastally trapped wind reversal based on numerical simulations and aircraft observations. Mon. Wea. Rev., 136, 4687-4708, https://doi.org/10.1175/2008MWR2361.1.

Ralph, F. M., L. Armi, J. M. Bane, C. Dorman, W. D. Neff, P. J. Neiman, W. Nuss, and P. O. Persson, 1998: Observations and analysis of the 10-11 June 1994 coastally trapped disturbance. Mon. Wea. Rev., 126, 2435-2465, https://doi.org/10.1175/1520 -0493(1998)126<2435:OAAOTJ>2.0.CO;2.

— , P. J. Neiman, J. M. Wilczak, P. O. Persson, J. M. Bane, M. L. Cancillo, and W. Nuss, 2000: Kelvin waves and internal bores in the marine boundary layer inversion and their relationship to coastally trapped wind reversals. Mon. Wea. Rev., 128, 283-300, https://doi.org/10.1175/1520 -0493(2000)128<0283:KWAIBI>2.0.CO;2.
Randall, D. A., J. A. Coakley, D. H. Lenschow, C. W. Fairall, and R. A. Kropfli, 1984: Outlook for research on subtropical marine stratification clouds. Bull. Amer. Meteor. Soc., 65, 1290-1301, https://doi .org/10.1175/1520-0477(1984)065<1290:OFROSM $>2.0 . \mathrm{CO} ; 2$.

Rausch, J., K. Meyer, R. Bennartz, and S. Platnick, 2017: Differences in liquid cloud droplet effective radius and number concentration estimates between MODIS collections 5.1 and 6 over global oceans. Atmos. Meas. Tech., 10, 2105-2116, https://doi.org /10.5194/amt-10-2105-2017.

Reason, C. J. C., and M. R. Jury, 1990: On the generation and propagation of the southern African coastal low. Quart. J. Roy. Meteor. Soc., 116, 1133-1151, https:// doi.org/10.1002/qj.49711649507.

— , K. J. Tory, and P. L. Jackson, 1999: Evolution of a southeast Australian coastally trapped disturbance. Meteor. Atmos. Phys., 70, 141-165, https://doi .org/10.1007/s007030050031.

Reid, H. J., and L. M. Leslie, 1999: Modeling coastally trapped wind surges over southeastern Australia. Part I: Timing and speed of propagation. Wea. Forecasting, 14, 53-66, https://doi.org/10.1175/1520 -0434(1999)014<0053:MCTWSO>2.0.CO;2.

Reynolds, R. W., and T. M. Smith, 1994: Improved global sea surface temperature analyses using optimum interpolation. J. Climate, 7, 929-948, https://doi .org/10.1175/1520-0442(1994)007<0929:IGSSTA $>2.0 . \mathrm{CO} ; 2$.

Seaman, C. J., and S. D. Miller, 2015: A dynamic scaling algorithm for the optimized digital display of VIIRS Day/Night Band imagery. Int. J. Remote Sens., 36, 1839-1854, https://doi.org/10.1080/01431161.2015 .1029100 .

Skamarock, W. C., R. Rotunno, and J. B. Klemp, 1999: Models of coastally trapped disturbances. J. Atmos. Sci., 56, 3349-3365, https://doi.org/10.1175/1520 -0469(1999)056<3349:MOCTD>2.0.CO;2.

—, J. B. Klemp, J. Dudhia, D. O. Gill, D. M. Barker, W. Wang, and J. G. Powers, 2008: A description of the Advanced Research WRF version 3. NCAR Tech. Note NCAR/TN-475+STR, 113 pp., https:// doi.org/10.5065/D68S4MVH.

Thompson, G., and T. Eidhammer, 2014: A study of aerosol impacts on clouds and precipitation development in a large winter cyclone. J. Atmos. Sci., 71, 3636-3658, https://doi.org/10.1175/JAS-D-13 -0305.1 .

Thompson, W. T., S. D. Burke, and J. Lewis, 2005: Fog and low clouds in a coastally trapped disturbance. J. Geophys. Res., 110, D18213, https://doi .org/10.1029/2004JD005522. 
Twohy, C. H., P. A. Durkee, B. J. Huebert, and R. J. Charlson, 1995: Effects of aerosol particles on the microphysics of coastal stratiform clouds. $J$. Climate, 8, 773-783, https://doi.org/10.1175/1520 -0442(1995)008<0773:EOAPOT>2.0.CO;2.

—, M. D. Petters, J. R. Snider, B. Stevens, W. Tahnk, M. Wetzel, L. Russell, and F. Burnet, 2005: Evaluation of the aerosol indirect effect in marine stratocumulus clouds: Droplet number, size, liquid water path, and radiative impact. J. Geophys. Res., 110, D08203, https://doi.org/10.1029/2004JD005116.

Twomey, S., 1977: The influence of pollution on the shortwave albedo of clouds. J. Atmos. Sci., 34, 1149-1152, https://doi.org/10.1175/1520-0469(1977)034<1149: TIOPOT $>2.0 . \mathrm{CO} ; 2$.

vanZanten, M. C., B. Stevens, G. Vali, and D. H. Lenschow, 2005: Observations of drizzle in nocturnal marine stratocumulus. J. Atmos. Sci., 62, 88-106, https://doi.org/10.1175/JAS-3355.1.

Villa, T. F., F. Gonzalez, B. Miljievi, Z. D. Ristovski, and L. Morawska, 2016: An overview of small unmanned aerial vehicles for air quality measurements: Present applications and future prospectives. Sensors, 16, 1072, https://doi.org/10.3390/s16071072.

Webb, M. J., and Coauthors, 2006: On the contribution of local feedback mechanisms to the range of climate sensitivity in two GCM ensembles. Climate Dyn., 27, 17-38, https://doi.org/10.1007/s00382-006 -0111-2.

Williams, A. P., R. Seager, J. T. Abatzoglou, B. I. Cook, J. E. Smerdon, and E. R. Cook, 2015: Contribution of anthropogenic warming to California drought during 2012-2014. Geophys. Res. Lett., 42, 68196828, https://doi.org/10.1002/2015GL064924.

Winant, C. D., R. C. Beardsley, and R. E. Davis, 1987: Moored wind, temperature, and current observations made during Coastal Ocean Dynamics Experiments 1 and 2 over the Northern California Continental Shelf and upper slope. J. Geophys. Res., 92, 15691604, https://doi.org/10.1029/JC092iC02p01569.

Wood, R., 2005: Drizzle in stratiform boundary layer clouds. Part I: Vertical and horizontal structure. J. Atmos. Sci., 62, 3011-3033, https://doi.org/10.1175 /JAS3529.1.

— 2012: Stratocumulus clouds. Mon. Wea. Rev., 140, 2373-2423, https://doi.org/10.1175/MWR-D -11-00121.1.

— between stratiform low cloud cover and lowertropospheric stability. J. Climate, 19, 6425-6432, https://doi.org/10.1175/JCLI3988.1.

_ and D. L. Hartmann, 2006: Spatial variability of liquid water path in marine low cloud: The importance of mesoscale cellular convection. J. Climate, 19, 1748-1764, https://doi.org/10.1175/JCLI3702.1.

Zemba, J., and C. A. Friehe, 1987: The marine boundary layer jet in the Coastal Ocean Dynamics Experiment. J. Geophys. Res., 92, 1489-1496, https:// doi.org/10.1029/JC092iC02p01489.

Zhang, Y., and J. Li, 2013: Shortwave cloud radiative forcing on major stratus cloud regions in AMIP-type simulations of CMIP3 and CMIP5 models. Adv. Atmos. Sci., 30, 884-907, https://doi.org/10.1007 /s00376-013-2153-9. 


\section{Radar and Atmospheric Science: A Collection of Essays in Honor of David Atlas}

Edited by Roger M. Wakimoto and Ramesh Srivastava

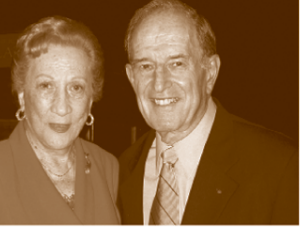

This monograph pays tribute to one of the leading scientists in meteorology, Dr. David Atlas. In addition to profiling the life and work of the acknowledged "Father of Radar Meteorology," this collection highlights many of the unique contributions he made to the understanding of the forcing and organization of convective systems, observation and modeling of atmospheric turbulence and waves, and cloud microphysical properties, among many other topics. It is hoped that this text will inspire the next generation of radar meteorologists, provide an excellent resource for scientists and educators, and serve as a historical record of the gathering of scholarly contributions honoring one of the most important meteorologists of our time.

Radar and Atmospheric Science: A Collection of Essays in Honor of David Atlas Aug 2003. Meteorological Monograph Series, Vol. 30, No. 52; 270 pp, hardbound; ISBN 1-878220-57-8; AMS code MM52.

Price $\$ 80.00$ member

To place an order point your Web browser to www.ametsoc.org/amsbookstore

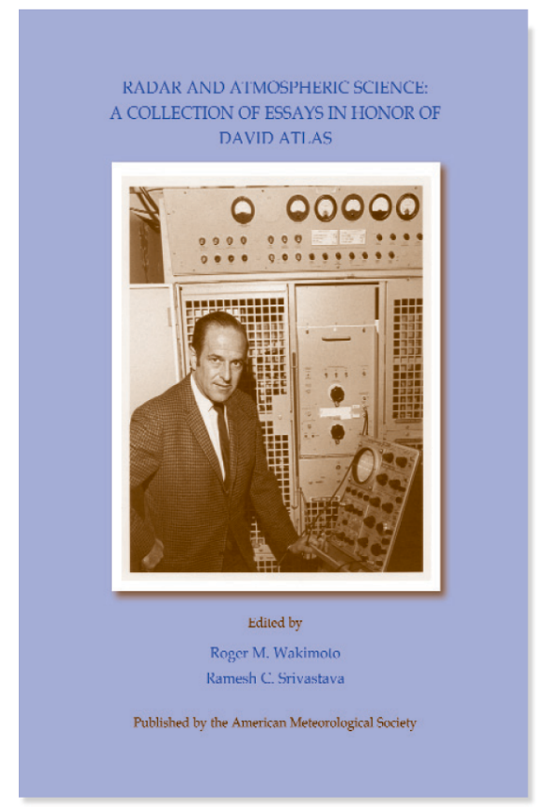

